\title{
Prediction of Food Craving Based on the Incompatible Domains of Personality with the mediating role of Non- Adaptive Strategies of Cognitive Emotion Regulation
}

\author{
Basharpoor. S \\ *Mosalman. $\mathrm{M}^{2}$ \\ 1- Ph.D. In Psychology, \\ Associate Professor, Faculty \\ of Educational Sciences and \\ Psychology, University of \\ Mohaghegh Ardabili, Ardabil, \\ Iran. \\ 2- ( ${ }^{*}$ Corresponding Auther) \\ Ph.D. Student of Psychology, \\ Faculty of Educational \\ Sciences and Psychology, \\ University of Mohaghegh \\ Ardabili, Ardabil, Iran. \\ Email:mahsa.mosalman@ \\ yahoo.com
}

\begin{abstract}
Introduction: Obesity and overweight are some problems in this century in the field of mental health.

Objective: This study was done to Predict food craving based on the incompatible domains of personality with the mediating role of non-adaptive strategies of cognitive emotion regulation.
\end{abstract}

Materials and Methods: The present study was descriptive-correlational, a type of path analysis model. The statistical population of this study was all students of Amol Institute in 2018-2019. A sample of 189 students was selected using the available sampling method and they responded to the Food Craving Questionnaire-Trait: FCQ-T, Cognitive Emotion Regulation Questionnaire (short form), and the Short Version of the Personality Questionnaire (DSM-5) (PID-5). Pearson correlation coefficient and regression-based path analysis were used to analyze the data.

Results: Independent variables of negative affection with dependent variable of food cravings $(r=0.207)$, antagonism with food craving $(r=0.234)$, disinhibition with food craving $(r=0.288)$, psychoticism with food craving $(r=0.267)$ and independent variables of negative affection with the mediating variable of non-adaptive strategies of cognitive emotion regulation $(\mathrm{r}=0.350)$, detachment with non-adaptive strategies of cognitive emotion regulation $(\mathrm{r}=0.217)$, disinhibition with non-adaptive strategies of cognitive emotion regulation $(\mathrm{r}=0.221)$, psychoticism with non-adaptive strategies of cognitive emotion regulation $(\mathrm{r}=0.172)$ and the mediator variable have a significant correlation between non-adaptive strategies of cognitive emotion regulation with dependent variable of food craving $(\mathrm{r}=0.243)$. On the other hand, the disinhibition trait $(\mathrm{P}=0.027)$, in addition to the direct effect, has an indirect effect due to nonadaptive strategies of cognitive emotion regulation on food craving $(\mathrm{P}=0.009)$.

Discussion and Conclusion: Finally, according to the findings, it can be concluded that the cognitive management of negative emotions plays a role in mediating the relationship between incompatible domains of personality with food craving. These results may provide tips for determining more effective steps to prevent overweight, obesity or low weight or weight control interventions.

Keyword: Food Craving-Trait, Incompatible Domains of Personality, NonAdaptive Strategies of Cognitive Emotion Regulation, Students. 


\section{يشينى ولع غذا براساس حيطههاى ناساز كار شخصيت با نقش ميانجى راهبر دهاى غير انطباقى تنظيم شناختى هيجان}

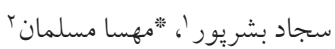

جكيده

مقدمه: جاقى و اضافه وزن يكى از عمدهترين معضلات قرن حاضر در حوزه سلامت عمومى به حساب مى آيد. هدف: يزوهش حاضر با هدف ييشبينى ولع غذا بر اساس حيطههاى ناساز گار شخصيت با نقش ميانجى راهبردهاى غيرانطباقى تنظيم شناختى هيجان انجام شد.

مواد و روشها: روش يزوهش از نوع مطالعات توصيفى - همبستگى (تحليل مسير) بود. جامعه آمارى اين يزوهش را تمامى

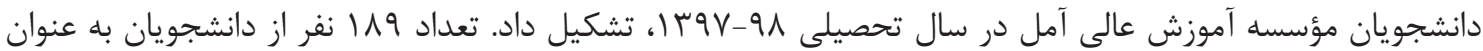
نمونه مورد نظر با استفاده از روش نمونه هيجان (فرم كوتاه) و نسخه كوتاه يرسشنامه شخصيت DSM-ه (PID-ه) ياسخ دادند. براى تجزيه و تحليل دادهها از ضريب همبستخى پيرسون و تحليل مسير مبتنى بر رگرسيون استفاده شد.

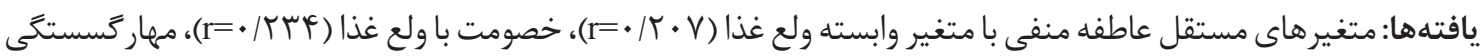

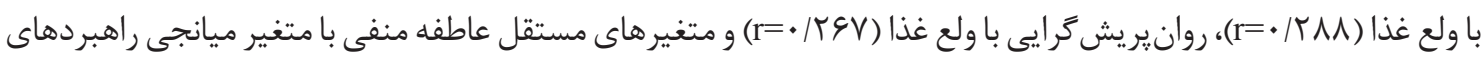

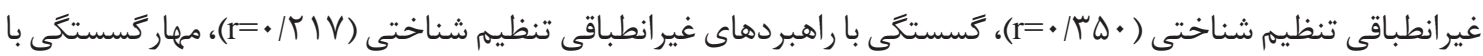

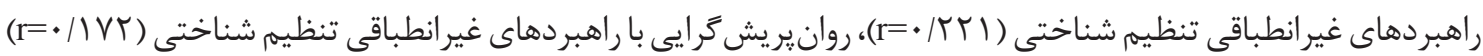
و متغير ميانجى راهبردهاى غيرانطباقى تنظيم شناختى با متغير وابسته ولع غذا (r=/F) •r= همبستخى معنادار دارند. از

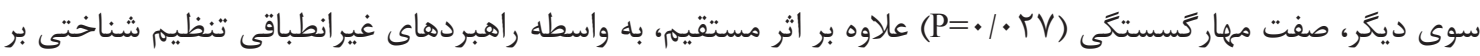

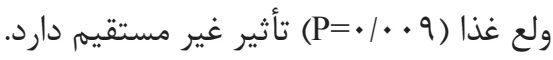

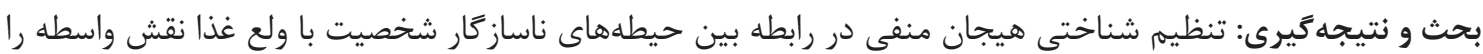
ايفا مى كند. اين نتايج ممكن است نكاتى را براى تعيين اقدامات مؤثرتر براى جلوگيرى از اضافه وزن، جاقى يا كم وزن يا مداخله كنترل وزن ارائه دهد.

كلمات كليدى: حيطههاى ناسازكار شخصيت، دانشجويان، راهبردهاى غيرانطباقى تنظيم شناختى، ولع غذا.

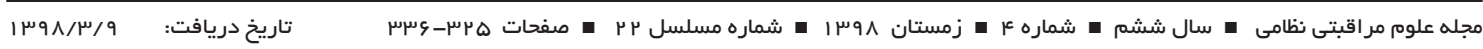

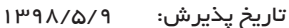

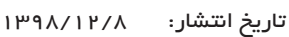

جاقى يك مسئله ممهم به شمار مىرود (1). هر جند اضافه وزن و مقدمه جاقى با مصرف بالاى غذا و به خصوص غذاهاى ير كالرى رابطه دارد، جاقى (Obesity) و اضافه وزن (Overweight) يكى از عمدهترين اما عوامل زيربنايى كه در رفتار مصرف بيش از اندازه غذا مؤثر است معضلات قرن حاضر در حوزه سلامت عمومى به حساب مى آيد ( (1). از ديدگاه بهداشت عمومى، گسترش مداخلههاى مؤثر بر درمان معلوم نيست (Y). در تلاش براى فهمم عوامل مؤثر در مصرف بيش 
بودن (Conscientiousness) توصيف مى كند، براى سطح نرمال

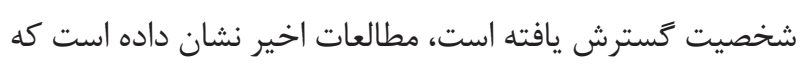

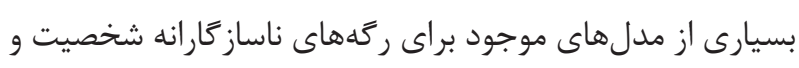
سبكهاى بين شخصى نيز بر اساس اين مدل طر احى شدهاند (ه ا ) .

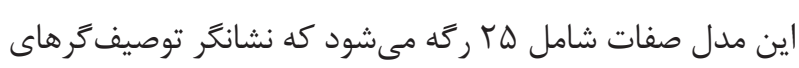

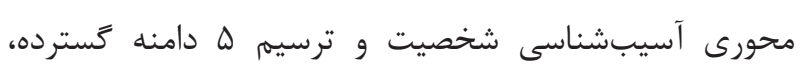

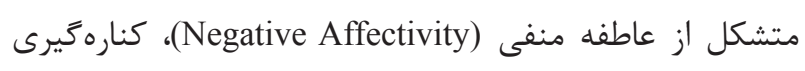

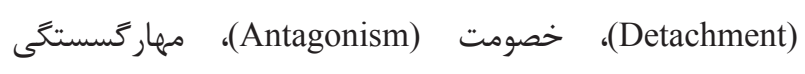
(Disinhibition)

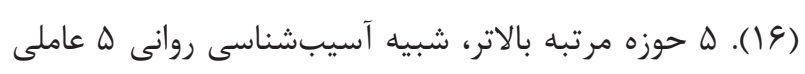

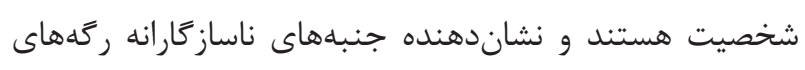

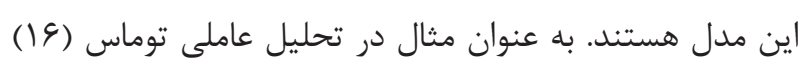

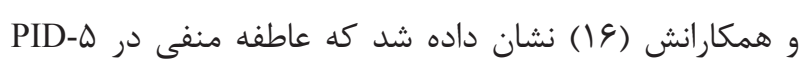

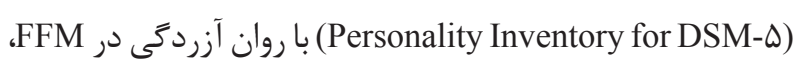
مقارن است و نيز كنارهزيرى با برون

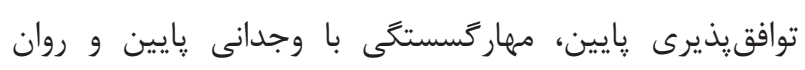
كسسته كرايى با باز بودن به تجربه همراستا هستند.

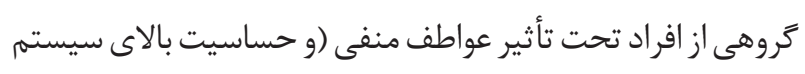

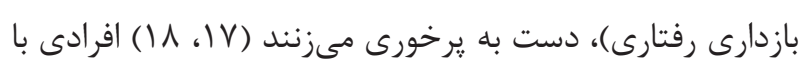

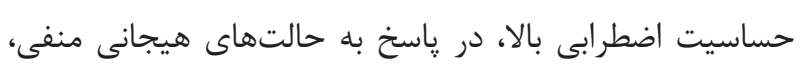

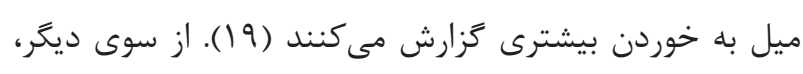
عاطفه منفى و فعاليت سيستم فعال سازى رفتارى در افراد مبتلا

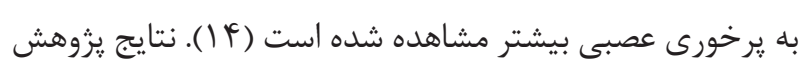

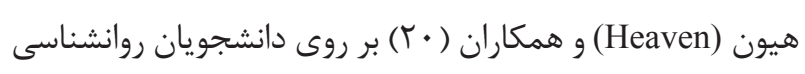

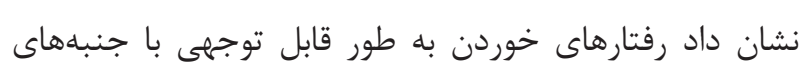
شخصيتى مرتبط با روانرنجورخويى و وظيفهشناسى ارتباط دارد. همجنين نتايج يزوهش كر لاج (Gerlach) و همكاران (Y) (Y) نشان

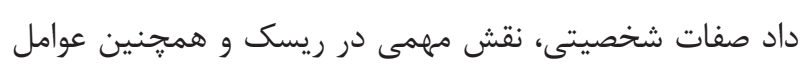

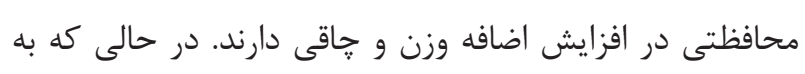

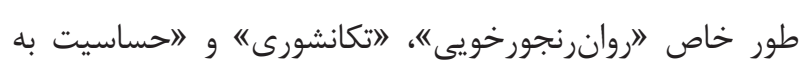

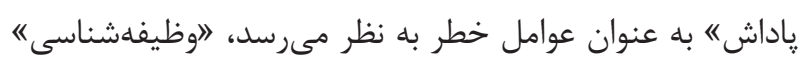

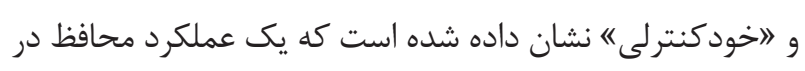
رابطه با افزايش وزن است. الفهاگ و مورى (Elfhag \& Morey)

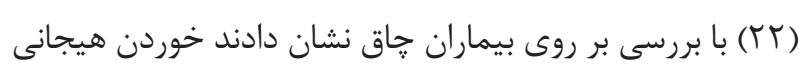

از حد غذا، يزوهشكران به طور فزايندهاى بر سازههاى اختصاصىتر خوردن همجون ولع به غذا (Food Craving) تمركز كردهاند

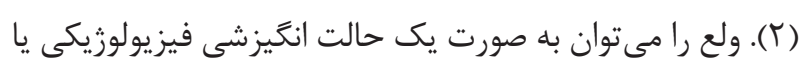
روانشناختى تعريف كرد كه رفتارهاى مادهويى و بلعى نسبت

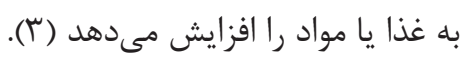

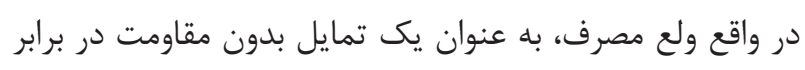

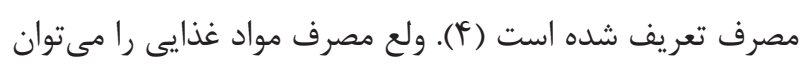

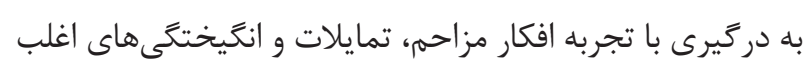

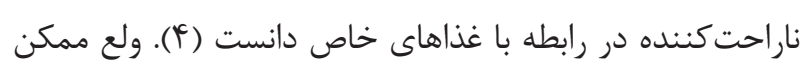

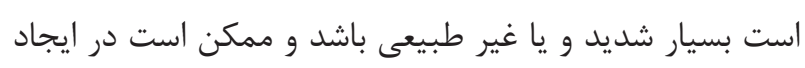

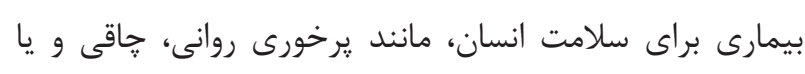

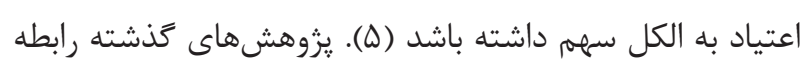

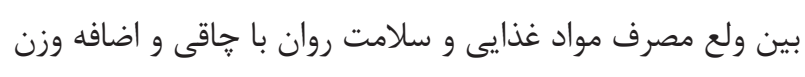
را نشان دادهاند (9). بسيارى از يزوهشكران تأثيرات زيستى در يديده ولع را كم اهميت دانسته و فرايندهاى روانشناختى را علت ولع در نظر مى بـيرند

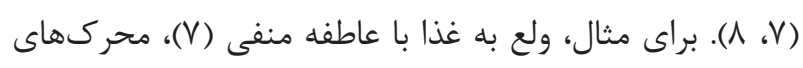

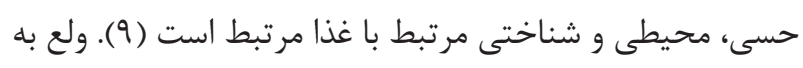
غذا با مشكلاتى نظير يرخورى افراطى (Binge Eating) و على علائم

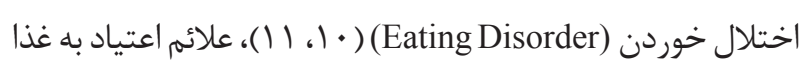

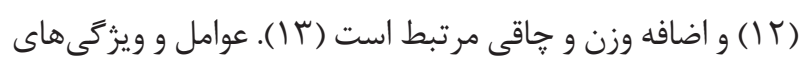

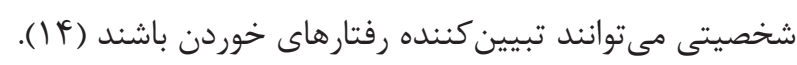
DSM-ه سيستمى را براى تشخيص اختلال شخصيت افراد ارائه

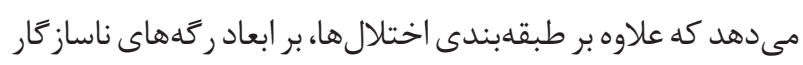

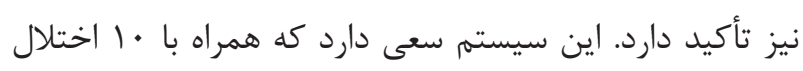

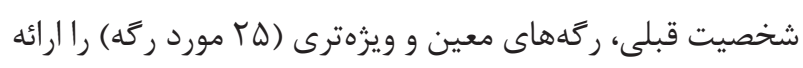

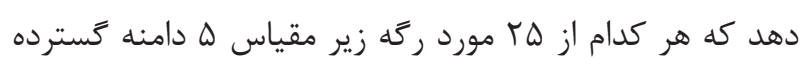

$$
\text { صفات مرضى شخصيت هستند. }
$$

مدل جامع شخصيت، به صورت كلى، هم از لحاظ مفهومى و هم هم هميتن

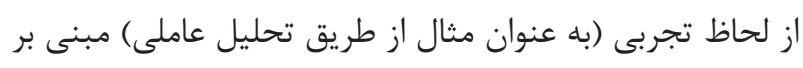
مدل ينج عاملى شخصيت (Five-Factor Model: FFM) است. احر جه مدل ينج عاملى كه شخصيت را دادر وازمهايى مانند روان

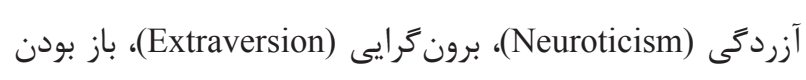

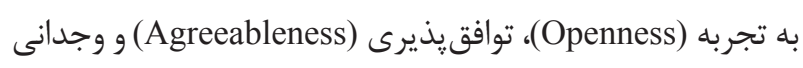




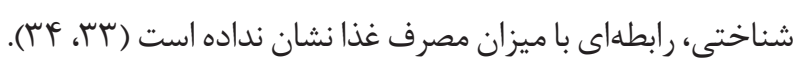

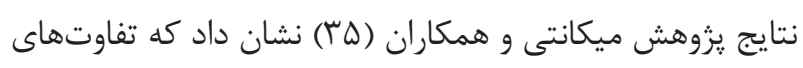
قابل توجهى از نظر آسيب شناسى روانى در ميان تمام رفتارهاى دمان خوردن و افزايش اختلال هيجانى و تعيين رفتارهاى ناساز

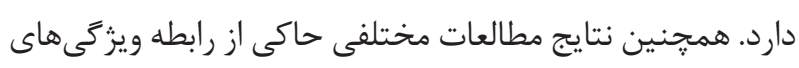

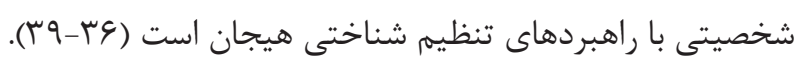

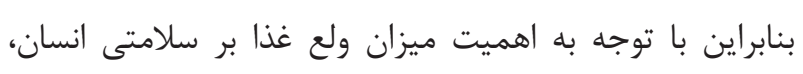

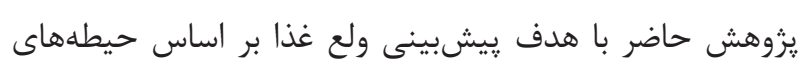

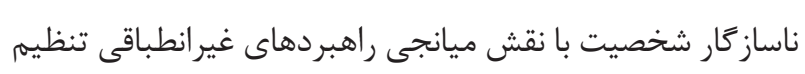

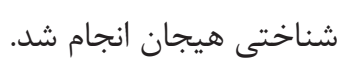

\section{مواد و روشها - - ماد}

اين يزوهش از مطالعات توصيفى و به روش همبستخى، از نوع مدل

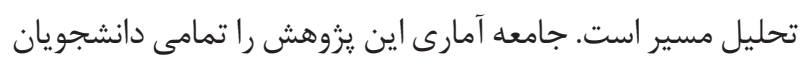

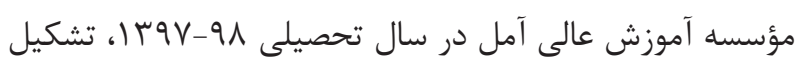
داد. طبق فرمول فيدل و تاباجنيك (Tabachnick \& Fidell) در ركرسيون جند إنه، اندازه نمونه با توجه به تعداد متغيرهاى

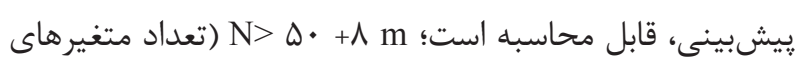

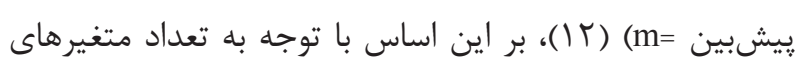

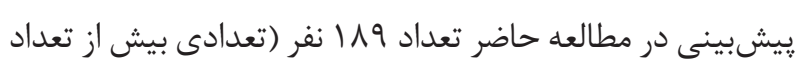

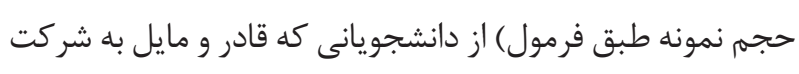

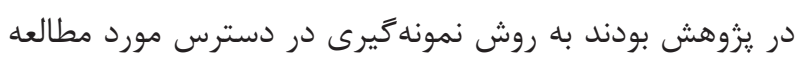

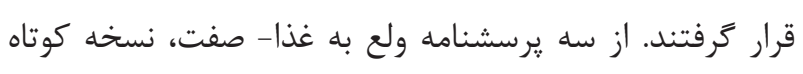
يرسشنامه شخصيت و مقياس تنظيم شناختى هيجان نسخه كوتاه

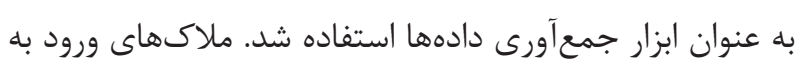

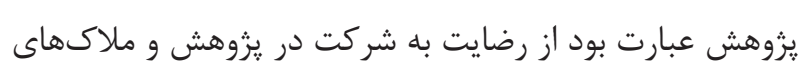
خروج خاصى تعيين نشد.

(Food Craving Questionnaire- يرسشنامه ولع به غذا- صفت تعين ندل از وج ماده تشكيل شده است و شدت ولع به - Trait: FCQ-T) غذا را در سطحى جند بعدى اندازه مى خيرد. ياسخها روى مقياس

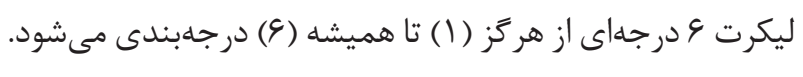

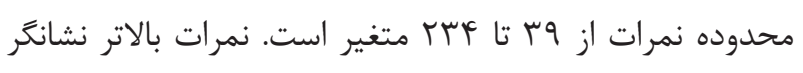

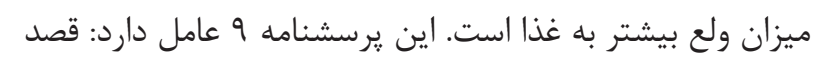
و برنامهريزى براى مصرف غذا (قصدها)، پِيشبينى تقويت مثبت
به شدت با روانرنجورخويى، به ويزه تكانشورى و افسردىى

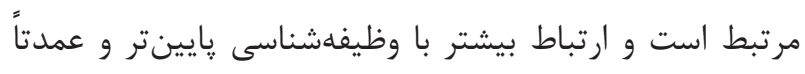

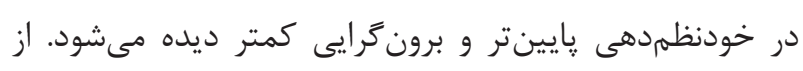

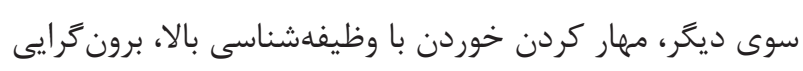

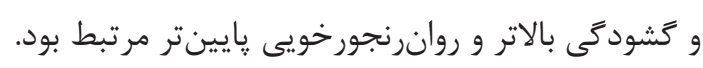

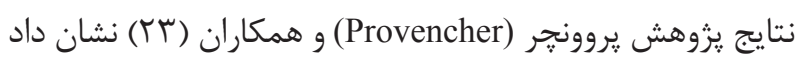

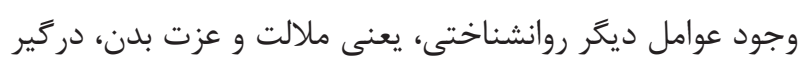

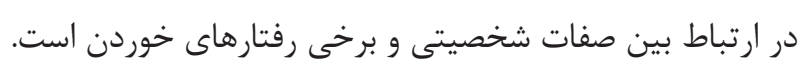

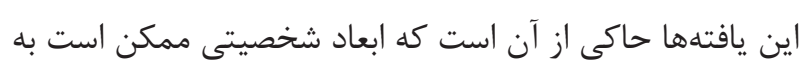

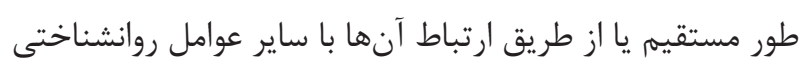

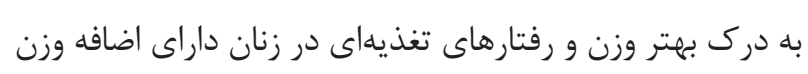
و جاقى كمك كند.

مطالعات مربوط به تنظيم هيجان تأكيد مى كنند كه خوردن،

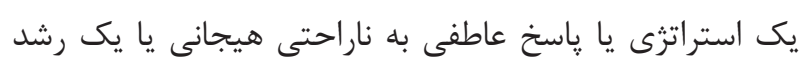

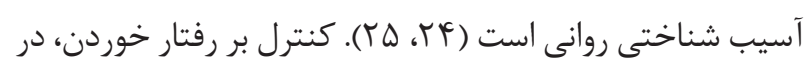
واقع از جمله فرآيندهايى است كه مرتبط با تنظيم هيجان است رونت

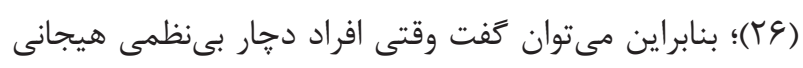

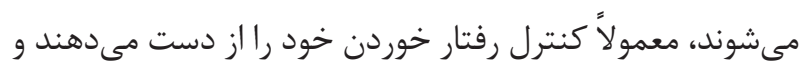
كنترل كمترى بر خوردن در موقعيتهاى هيجانى دارند يعنى از راهبردهاى غيرانطباقى تنظيم شناختى هيجان استفاده مى كنند

تنظيم هيجان از طريق افكار و شناخت، با زندگى افراد مرتبط

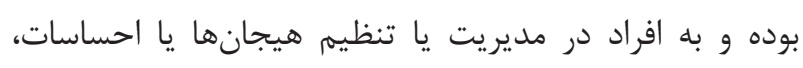

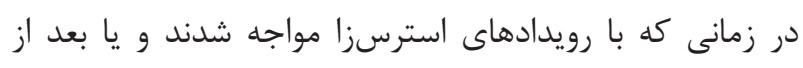

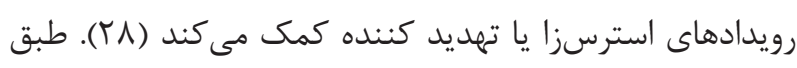

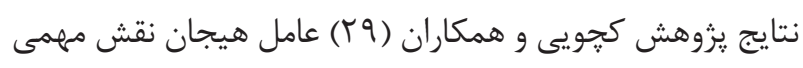

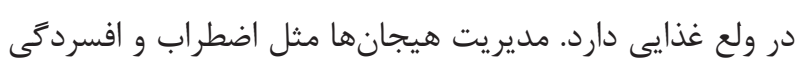

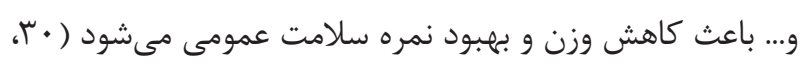

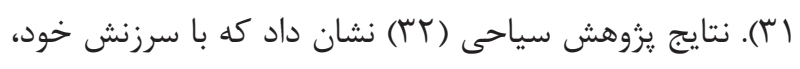
نشخوارگرىى، فاجعهآميزى كه از ابعاد تنظيم شناختى هيجان

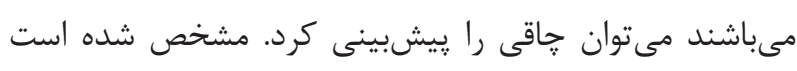

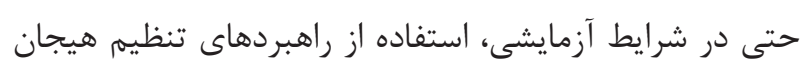

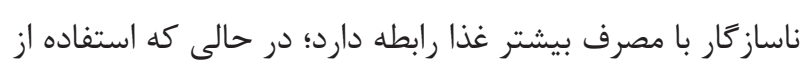
راهبردهاى تنظيم شناختى هيجان ساز ₹ار، مانند ارزيابى مجدد دارد 


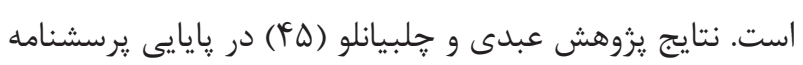

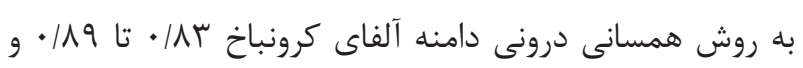

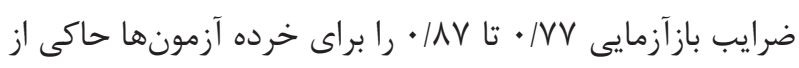
قايايى مطلوب نسخه فارسى اين يرسشنامه بود.

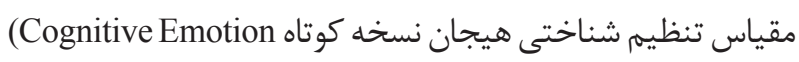
Regulation Questionnaire (Short Form)) است و راهبردهاى تنظيم شناختى هيجانها رادر ياسخ به حوادث

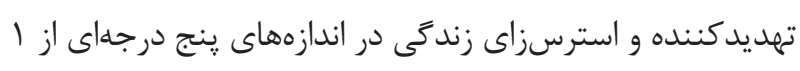

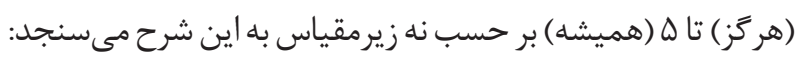

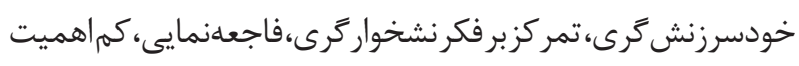
شمارى، تمركز مجدد مثبت، ارزيابى مجدد مثبت، يذيرش، تمركز

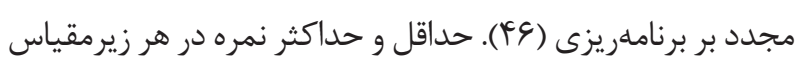

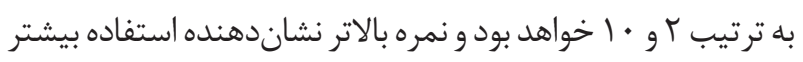

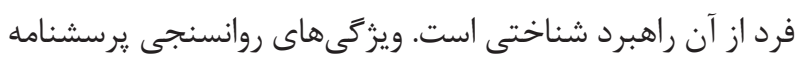

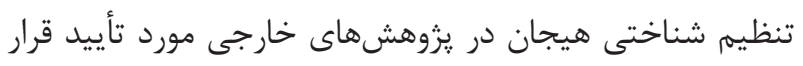

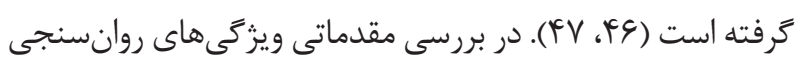

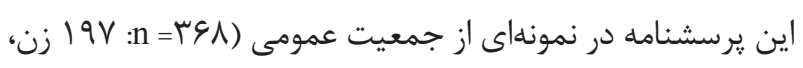

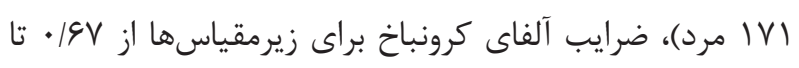

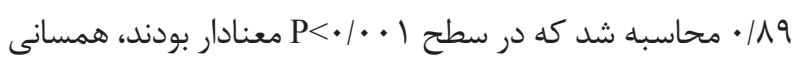

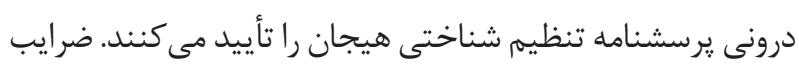

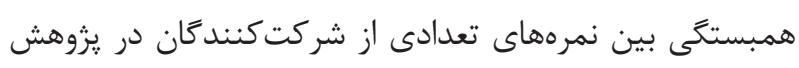

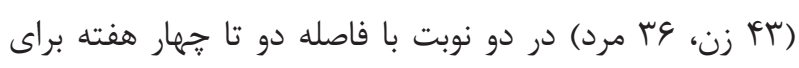

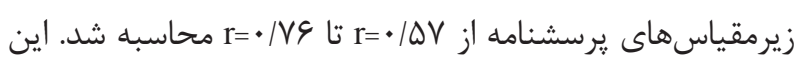

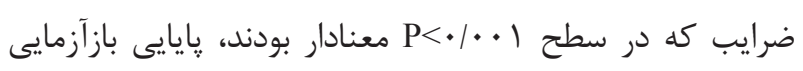

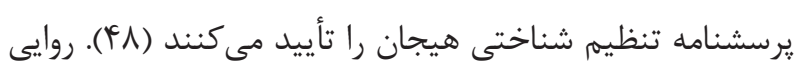

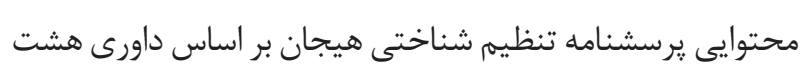
نفر از متخصصان روانشناسى بررسى و ضرايب توافق كندال براى نرسن

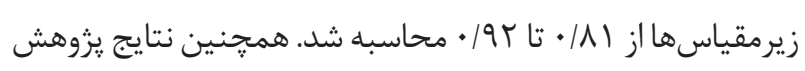

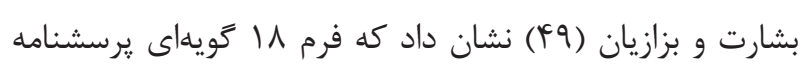

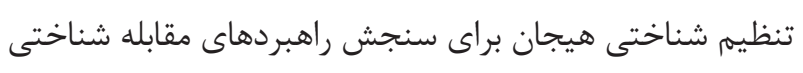
در نمونهاى ايرانى از بايايى و روايى كافى برخوردار است.

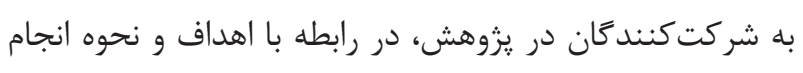

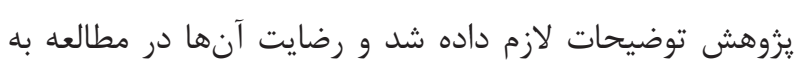
صورت شفاهى جلب شد. بر محرمانه بودن اين اطلاعات نيز تأكيد
در نتيجه خوردن (تقويت مثبت)، پِيشبينى رهايى از حالات و

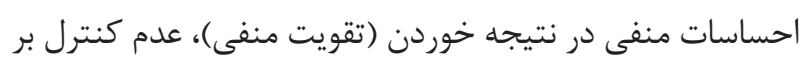
خوردن (فقدان كنترل)، افكار يا اشتغال ذهنى با غذا (افكار)، ولع

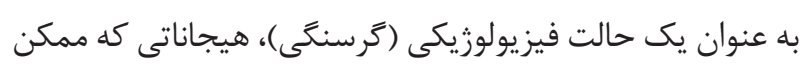
است بعد از يادر حين ولع به غذا يا خوردن تجربه شوند (هيجانات)، نشانههايى كه ممكن است راهانداز ولع به غذا شوند (نشانهها) و و احساس كناه به خاطر ولع و يا تسليم شدن در برابر آن (كَناه).

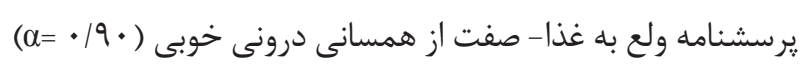

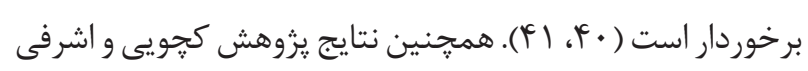

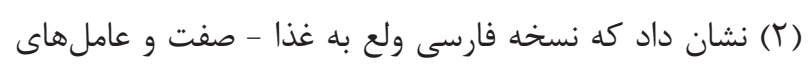

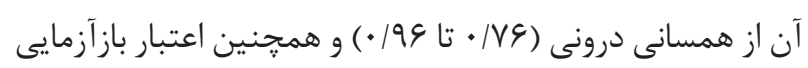

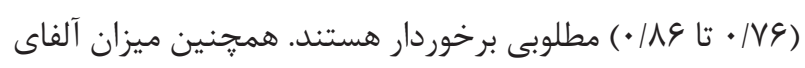

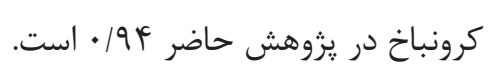

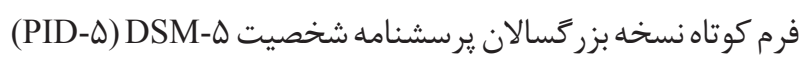

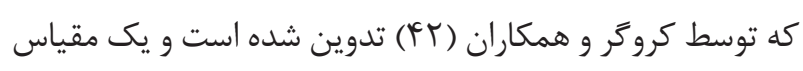

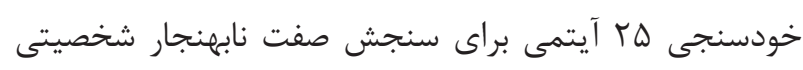

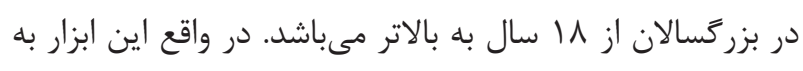

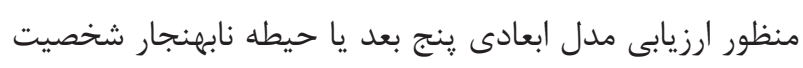
طراحى شده و مادهاى مستخرج آن در هر حيطه يا بعد شامل

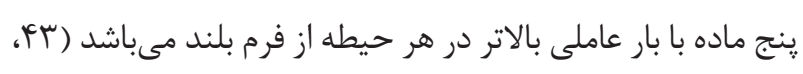

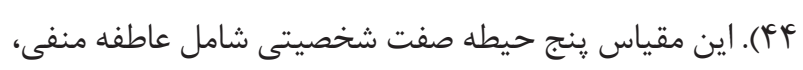

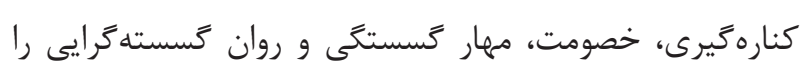

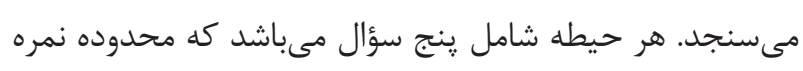

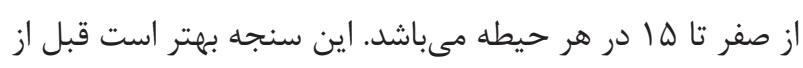
ملاقات متخصصان بالينى تكميل گردد. در همه آيتمها از افراد

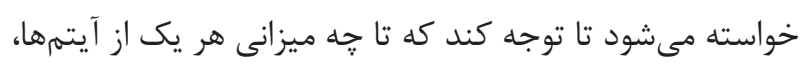

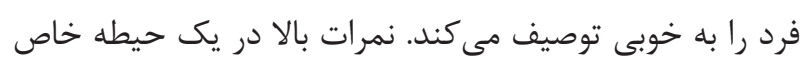

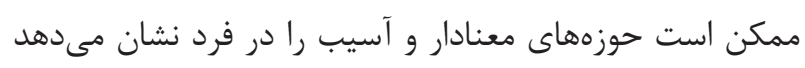

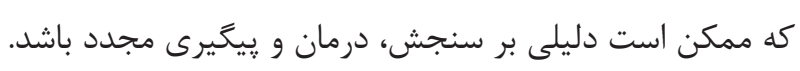

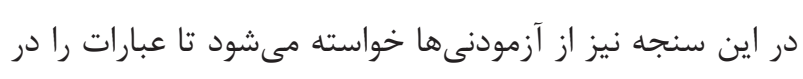

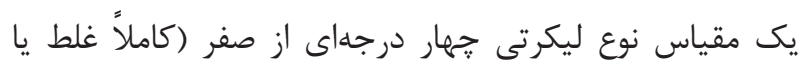

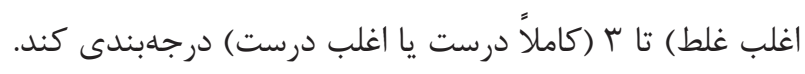

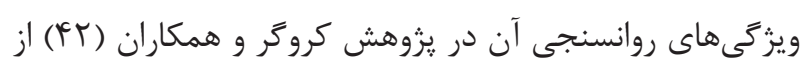

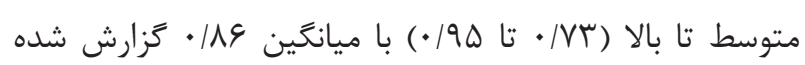


دانشجويان مؤسسه آموزش عالى آمل بودند كه ميانگين و انحراف

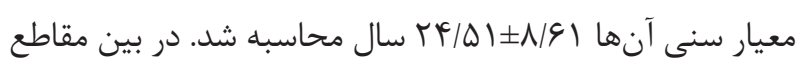

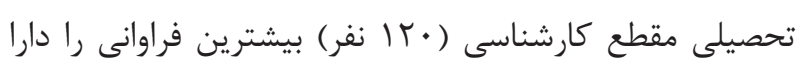
مىباشد. بر مبناى توصيفات ارائه شده در قسمتهاى قبلى، يزوهش حاضر

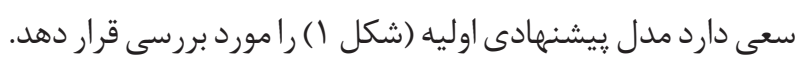

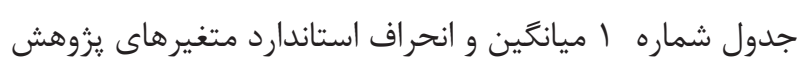

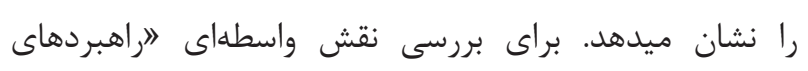

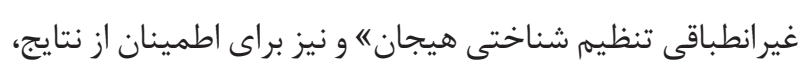

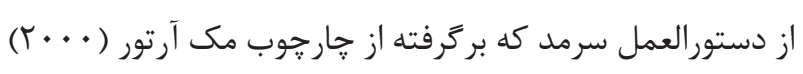

جدول ا- ميانغين، انحراف استاندارد متغيرهاى يزوهش

\begin{tabular}{|c|c|c|}
\hline انحراف معيار & ميانغين & متغير \\
\hline$r \cdot l \cdot v$ & $1 \cdot r / \wedge G$ & ولع غذا \\
\hline$r / r)$ & $9 / 0$. & عاطفه منفى \\
\hline T/9T & F/AV & كنارهگيرى \\
\hline$r / 99$ & $F / D \mid$ & خصومت \\
\hline$r / \cdot r$ & $F / \Delta \varphi$ & مهار گَستتخى \\
\hline$r / \cdots$ & $\Delta / \cdot r$ & روانيريش گرايى \\
\hline $9 / 99$ & $r \cdot / \Lambda V$ & شناختى هيجان رانداى غيرانطباقى تنظيم \\
\hline
\end{tabular}

شد. يس از انتخاب نمونههاى موردنظر، از دانشجويان خواسته شد

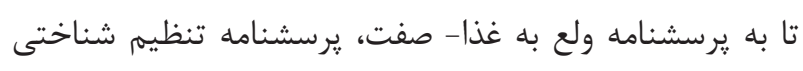

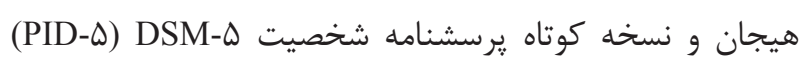

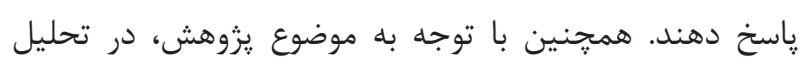

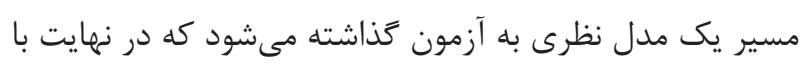
اجراى تحليل، اين مدل نظرى به يك مدل تجربى منجر شود.

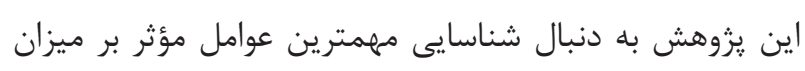

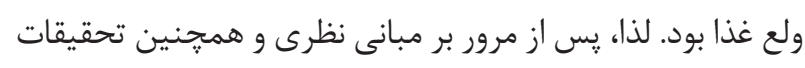
قبلى، مدل نظرى و مفهومى تحقيق تنظيم شد. سيس بـ به آزمون

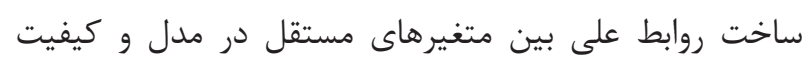

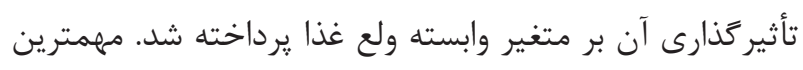

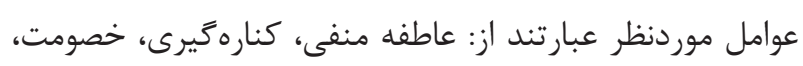

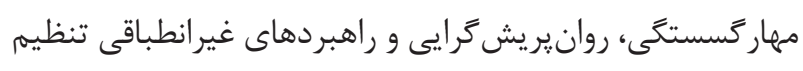

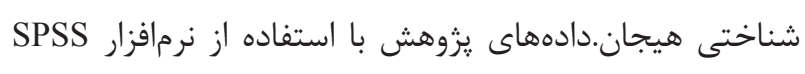
نسخه · r و با روش هاى آمار توصيفى (ميانخين و انحراف معيار) و ضريب همبستگى ضيرسون و تحليل مسير مبتنى بر تحليل ركرسيون در سطح معنى دارى ه • • تجزيه و تحليل شدند.

\section{يافتهها}

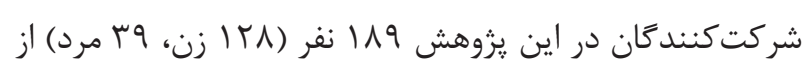

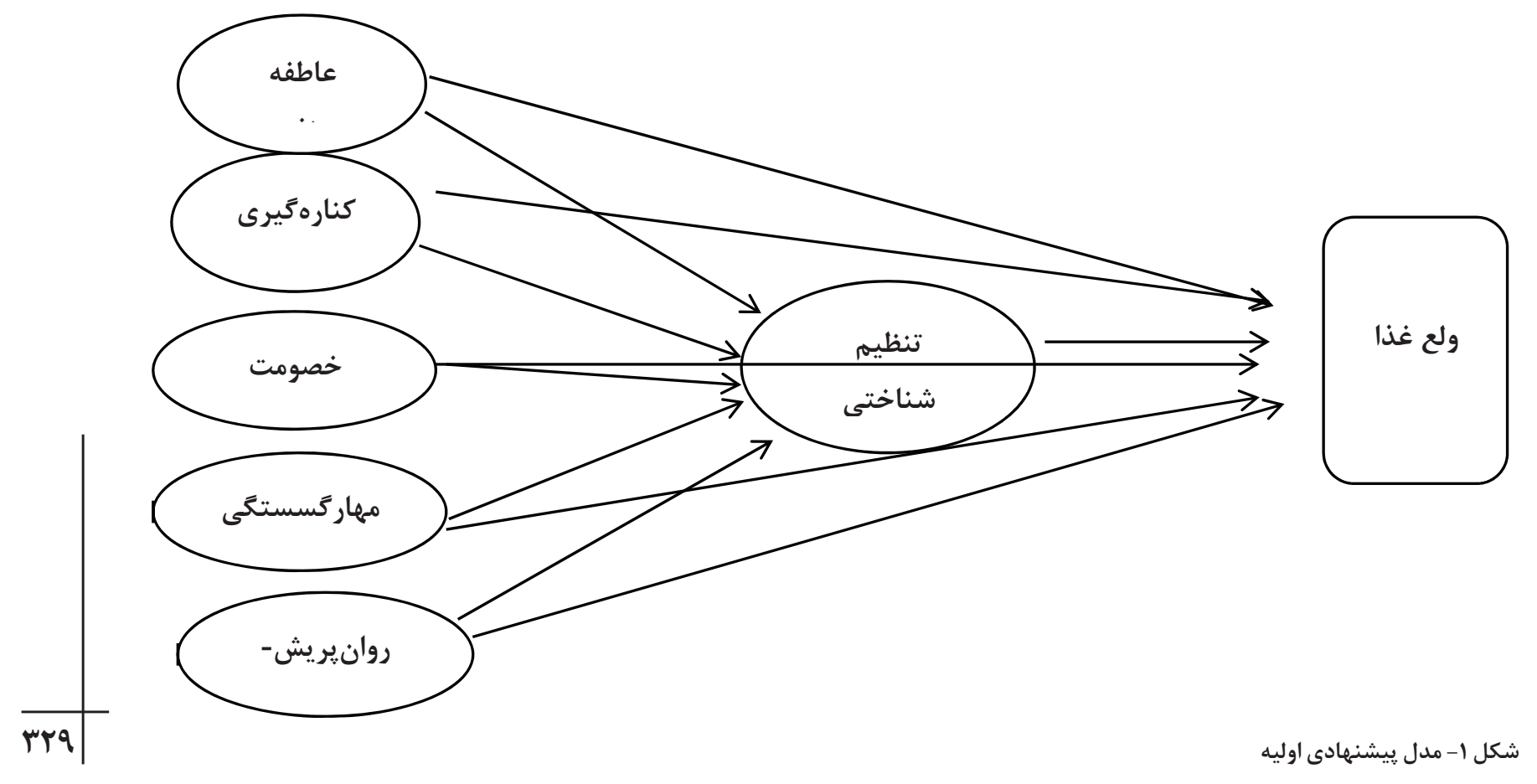


آنها با ولع غذا بررسى مىشود. در كام دوم متغير واسطهاى يا

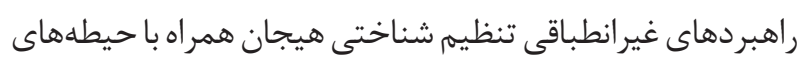
ناساز

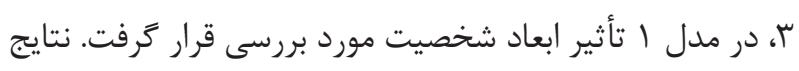

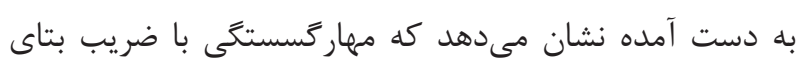

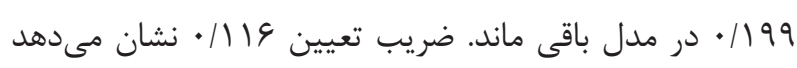
كه 11 درصد از واريانس متغير وابسته توسط متغير باقىمانده

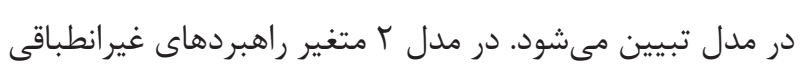

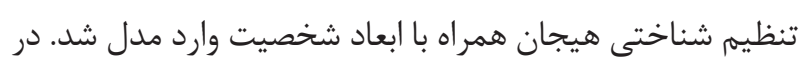

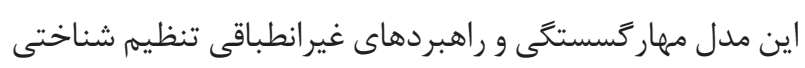

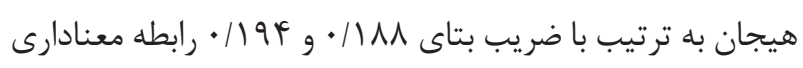

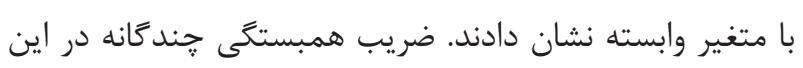

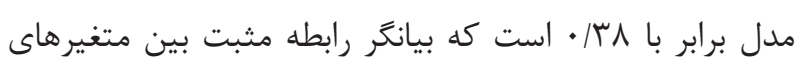

مىباشد و همجنين دستورالعمل بارون و كنى (9 (9 ) استفاده

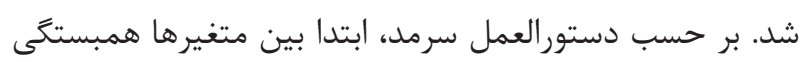

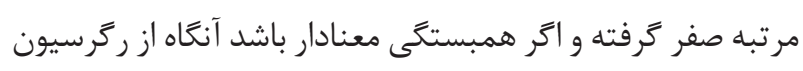

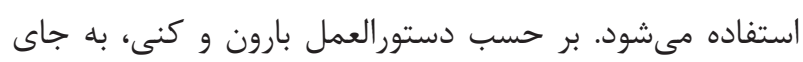

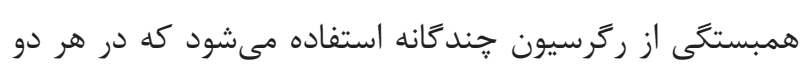

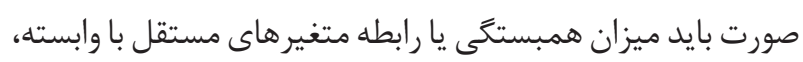

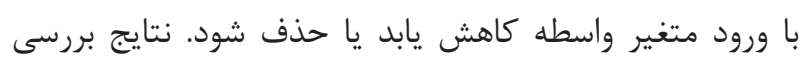

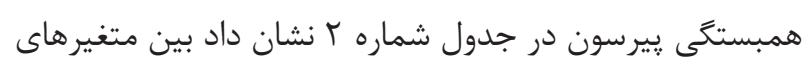

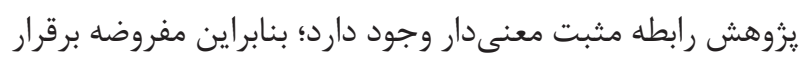
است و مىتوان از ركرسيون استفاده كرد.

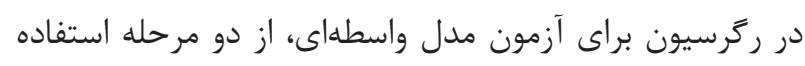

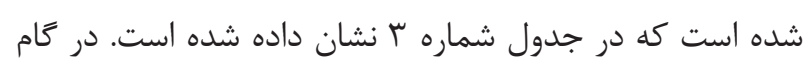

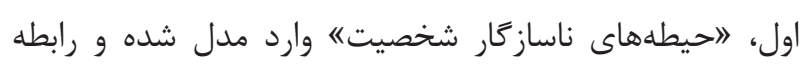

جدول r - ماتر يس همبستخى بين متغير هاى يثوهش

\begin{tabular}{|c|c|c|c|c|c|c|c|}
\hline V & 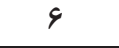 & $\Delta$ & r & r & r & 1 & 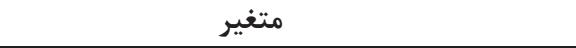 \\
\hline & & & & & & 1 & ا. ولع غذا \\
\hline & & & & & 1 & $\cdot / T \cdot V^{* * *}$ & ז. عاطفه منفى \\
\hline & & & & 1 & $\cdot / 49 \cdot * * *$ & . & س. كنارهخيرى \\
\hline & & & 1 & $\cdot 10 \cdot \Delta^{* * *}$ & $\cdot / \pi \cdot 9^{* * *}$ & 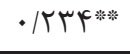 & | أ. خصومت \\
\hline & & 1 & $\cdot / \mathbb{F} \Delta \Delta^{* * *}$ & $\cdot 10 \cdot{ }^{* * * *}$ & $\cdot \mid 4 \& Y^{4}$ & $\cdot / r \Lambda \Lambda^{* * *}$ & 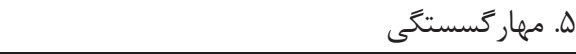 \\
\hline & 1 & $\left.\cdot|\Delta|\right|^{* * *}$ & $\cdot \mid \Delta q Y^{* * *}$ & $\cdot / \Delta \Gamma q * *$ & •/FVM"** & $\cdot / T S V^{* * *}$ & 9. روانيريش \\
\hline 1 & $\cdot / 1 V Y^{*}$ & $\cdot|T Y|^{* * * *}$ & $.111 \mathrm{~F}$ & $\cdot / r \mid V^{* * *}$ & $\cdot / \Gamma \Delta \cdot * * *$ & 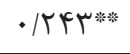 & V. راهبردهاى غيرانطباقى تنظيم شناختى هيجان \\
\hline
\end{tabular}

جدول ب- نتايج تحليل ركرسيون جندكَانه همزمان بين متغير هاى بثوهش

\begin{tabular}{|c|c|c|c|c|c|c|}
\hline \multicolumn{3}{|c|}{ مدل r } & \multicolumn{3}{|c|}{ مدل 1} & \multirow{2}{*}{ 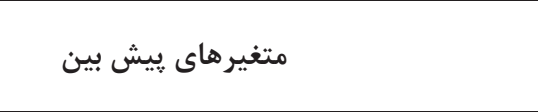 } \\
\hline Sig & B & B & Sig & B & B & \\
\hline $.19 V$ & $-\cdot / \cdot r$ & $-\cdot \cdot \cdot r \cdot$ & $\cdot / \mathcal{F} \wedge \mathrm{F}$ & $\cdot / \cdot \Delta \Lambda$ & $\cdot|\Delta F|$ & عاطفه منفى \\
\hline .1119 & $-\cdot / 1 \mathrm{f}$ & 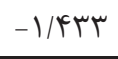 &.$/ 19 \mathrm{~V}$ & -.1119 & $-1 / 1 \wedge \wedge$ & كنارهزيرى \\
\hline .1199 & . & $1 / 1 r \Delta$ & - ITFT & $\cdot / 1 \cdot \Delta$ & $1 / .49$ & خصومت \\
\hline$\cdot / \cdot r k$ & $\cdot 1111$ & $1 / \wedge 9$ & $\cdot 1 \cdot r V$ & .1199 & 1/9Vr & مهار كستتخى \\
\hline .1119 & .1149 & $1 / 490$ & $\cdot 110$ & $\cdot 114$ & $1 / 4 \cdots$ & روانيريش \\
\hline \multirow[t]{5}{*}{$.1 \cdot 99$} & $\cdot 1194$ & •/Ard & & & & راهبردهاى غيرانطباقى تنظيم شناختى هيجان \\
\hline & $\cdot / r \wedge \Delta$ & & & $\cdot / \mu r \cdot$ & & $\mathrm{R}$ \\
\hline & $\cdot / 14 \lambda$ & & & .1119 & & $\mathrm{R}^{r}$ \\
\hline &.$/ 1 T \cdot$ & & & .1 .94 & & تعديل شده Rr \\
\hline & $\cdot 1 \cdot \cdots$ & & & $\cdot 1 \cdots$ & & سطح معنادارى \\
\hline
\end{tabular}




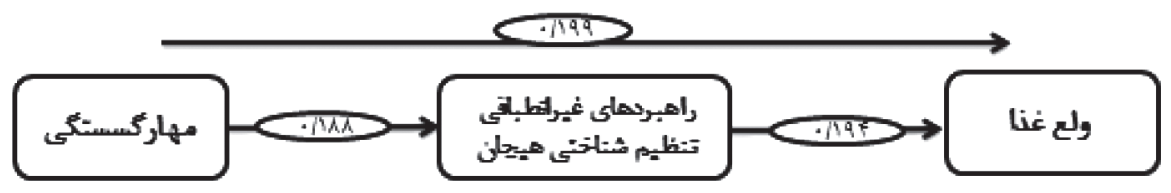

شكل r - مدل نهايى تحليل مسير يس از بر آورد ضرايب مسير

ميزان ولع غذا تأثير معنادار دارد. و فرضيه غيرمستقيم: حيطههاى ناسازكار شخصيت از طريق

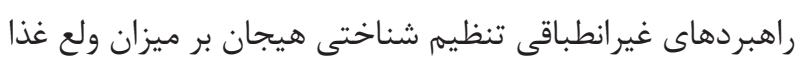
تأثير معنادار دارد. مورد تأييد قرار كرفت.

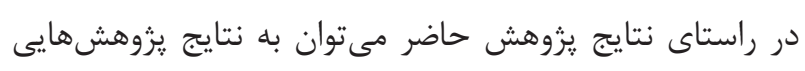

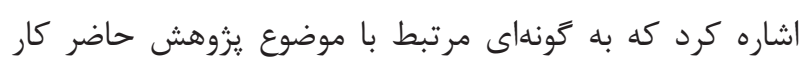

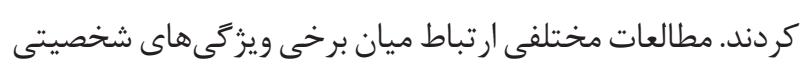

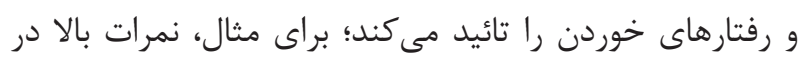

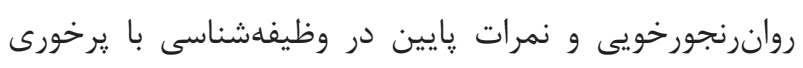

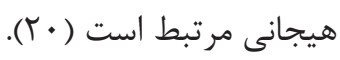

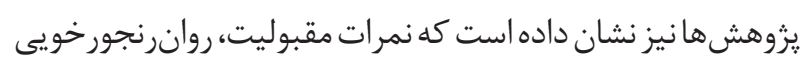
و وظيفهشناسى، در ييشبينى فههم بهتر رفتارهاى خوردن مؤثر

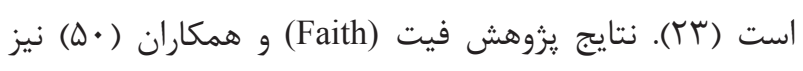

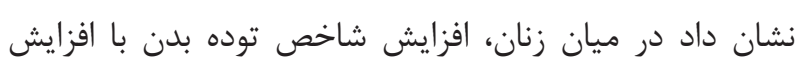

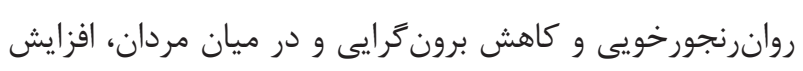

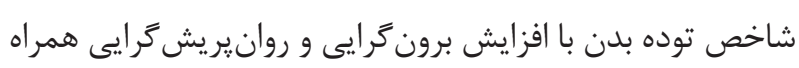

نتايج يزوهش بهزادى يور و همكاران (1) نشان داد داد افراد

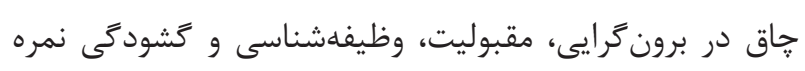

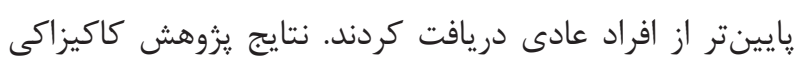
و همكاران (Kakizaki)

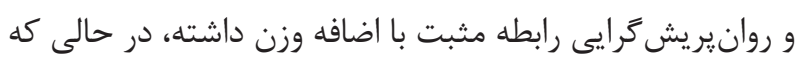
روانرنجورخويى ارتباط معكوس داشت. در مردان و زنان تنها،

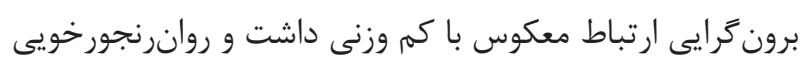

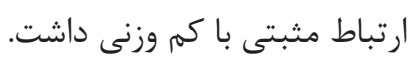
روانرنجورخويى، در واقع با اضطراب، خشونت، افسردى دئ، كمرويى،

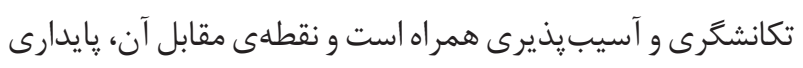

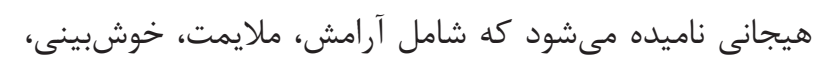

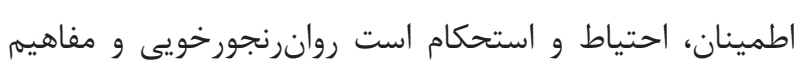

مستقل با وابسته است. ضريب تعيين برابر با \& | | ب بيانكر اين

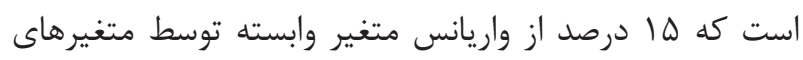
مهار گسستخى و راهبردهاى غيرانطباقى تنظيم شناختى هيجان تبيين مىشود. اين اطلاعات كمك مى كنند تا رابطه حيطههاى رهاى

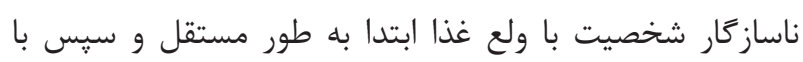
همراهى متغير راهبردهاى غير انطباقى تنظيم شناختى هيجان

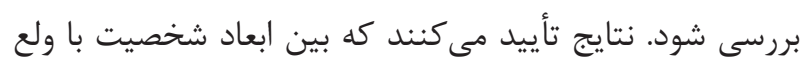

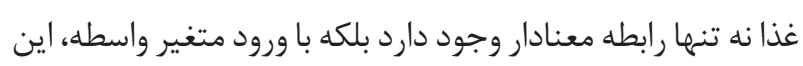

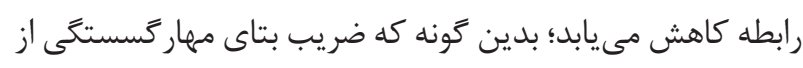

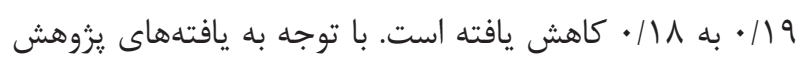
فرضيههاى يزوهش مورد تائيد قرار گرفت.

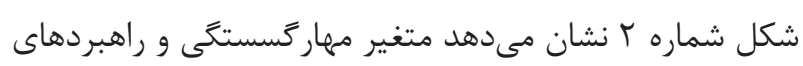

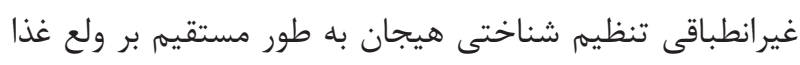

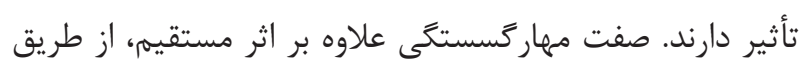

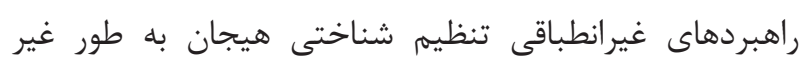
مستقيم نيز بر متغير وابسته تأثير كذار است.

\section{بحث و نتيجه كيرى}

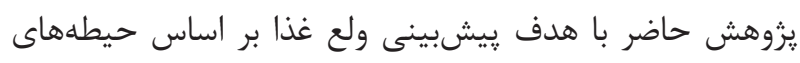

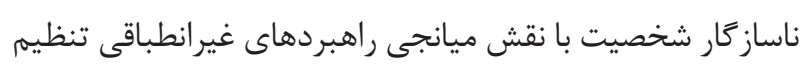

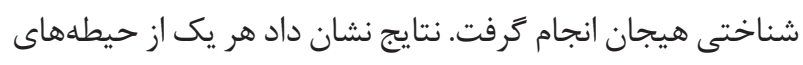

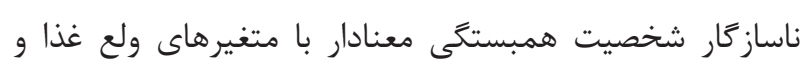
راهبردهاى غيرانطباقى تنظيم شناختى هيجان دارند و همجنين منين

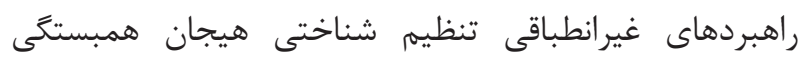

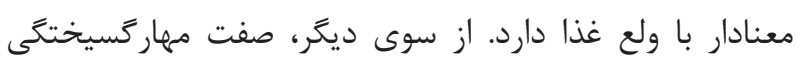
(متغير مستقل) علاوه بر اثر مستقيه بر ولع غذا (متغير وابسته)،

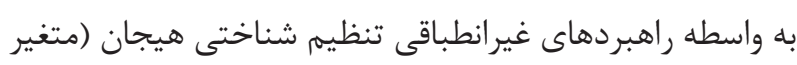

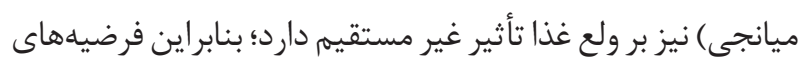

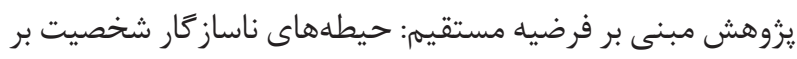


عمل كردن بدون فكر، هيجان طلبى و ناتوانى در اتمام كارها است

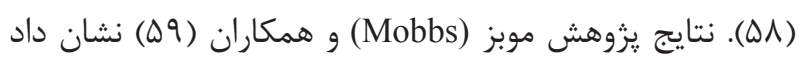

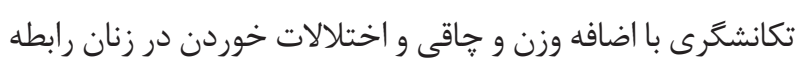
مثبت معنادار است.

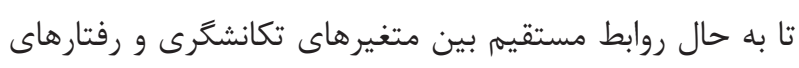

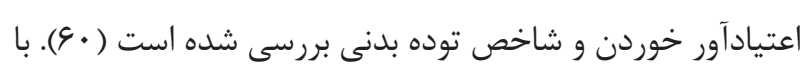

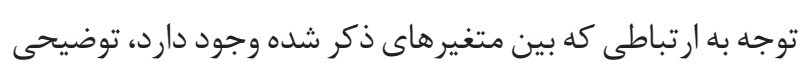

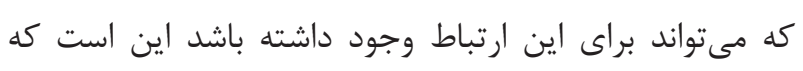
تكانشكرى منجر به رفتارهاى اعتيادى به مواد غذايى مى آنود كه آنه

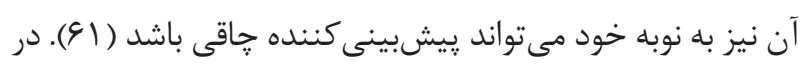

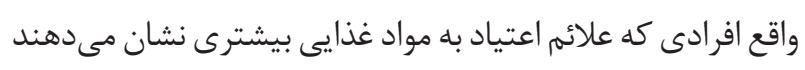

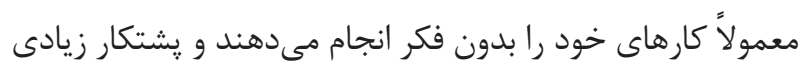

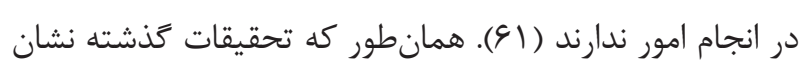
دادهاند افراد جاق سطوح بالاترى از فوريت منفى و فقدان يشتكار

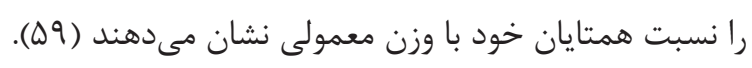

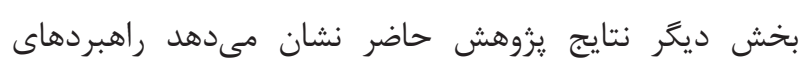

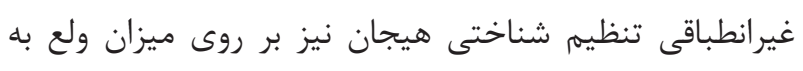

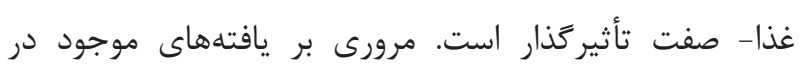

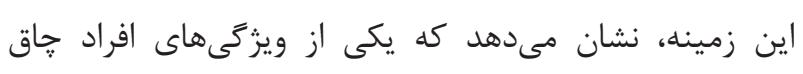

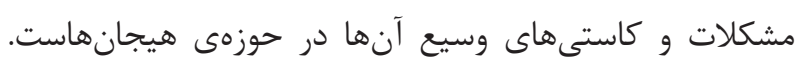

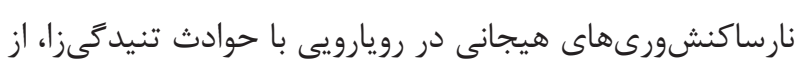

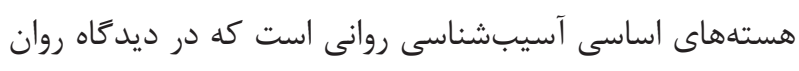
تحليل گرى، با عنوان مكانيزمهاى دفاعى صورتبندى شده است است

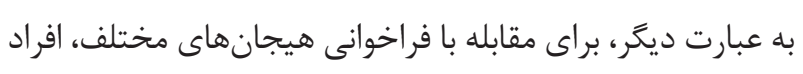
از الكوها و سبكهاى دفاعى خاصى استفاده مى كنند (T) (Y). نتايج

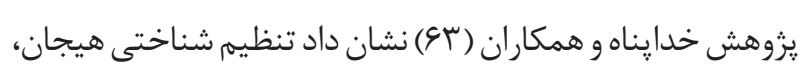
نقش مهمى در يِيشبينى رفتارهاى خوردن افراد داراى اضافه وزن و جاقى ايفا مى كند.

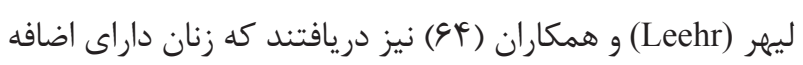

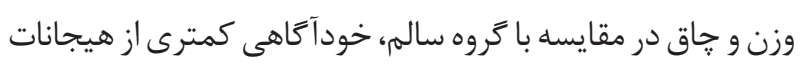
خود دارند و در تنظيم هيجانات خود با مشكل مواجه هستند.

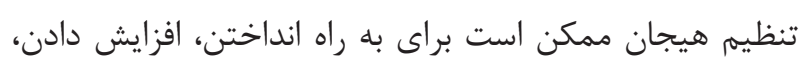

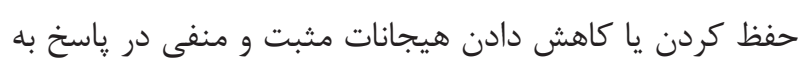

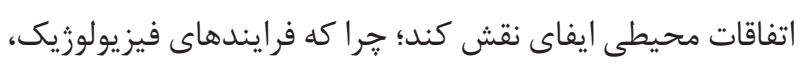

مرتبط با آن مانند بدبينى و هيجانات منفى، با تعبير و تفسير

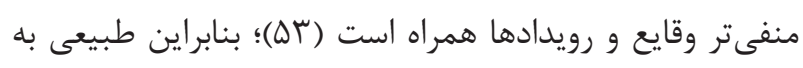
نظر مىرسد كه هرجه ميزان روانرنجورخويى فرد، بالاتر باشد روند

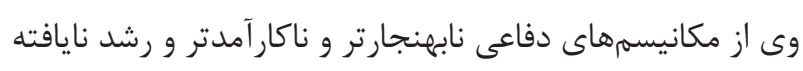

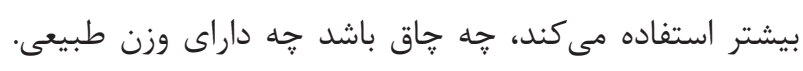

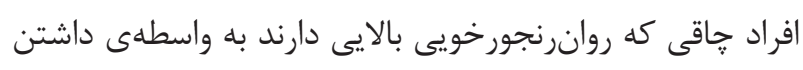
خصوصياتى كه به آنها اشاره شد از شناخت، تشخيص و توان كافى به منظور به كار گيرى فرونشانى و والايش كه كار آمدترين و

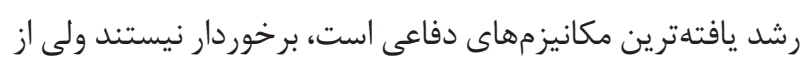

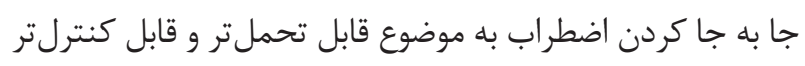

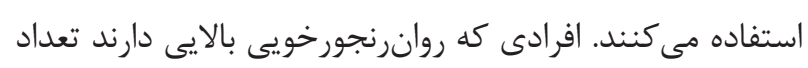

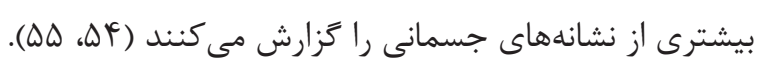

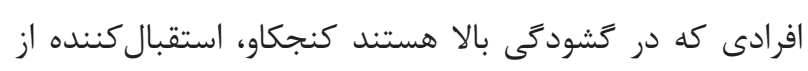

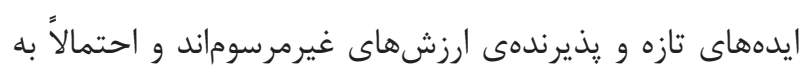
همين دليل افراد خاق، نيازى به تغيير مسير تكانههاى نامقبول

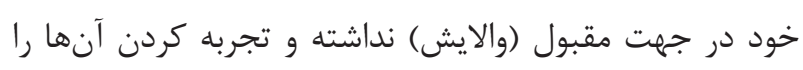

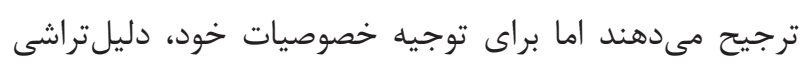
مى كنند (b) (ه).

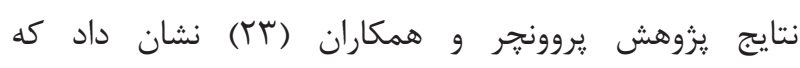
وظيفهشناسى با شاخص توده بدن رابطه مثبت دارد. سطح

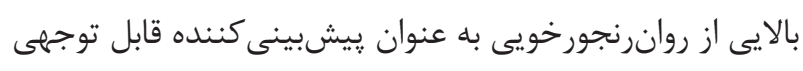

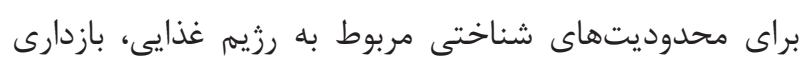

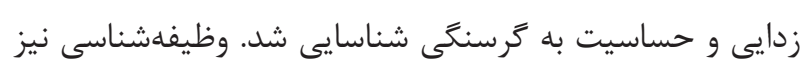

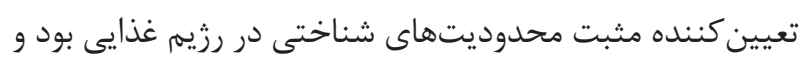

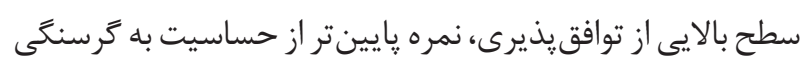
را ييشبينى كرد.

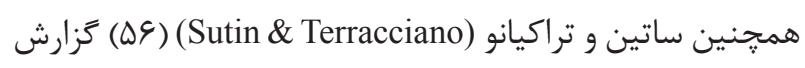
كردند بين روان نزندى و شاخص توده بدنى ارتباط وجود دارد و

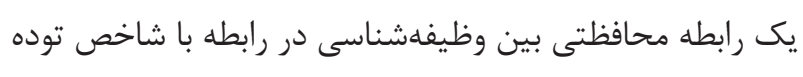
بدنى يايينتر بود.

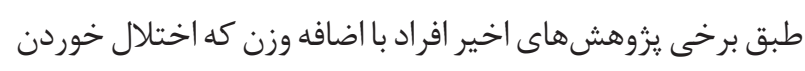
مفرط داشتند و تشخيص اعتياد به مواد غذايى را دريافت كرده بره

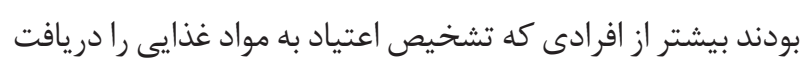
نكرده بودند، تكانشخرى بيشترى داشتند (DV). تكانشكرى شامل 
تبيين ديكرى كه مىتوان براى رابطه تنظيم هيجان با خوردن

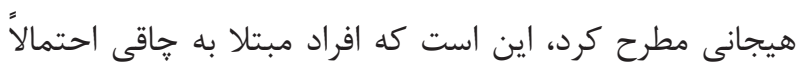

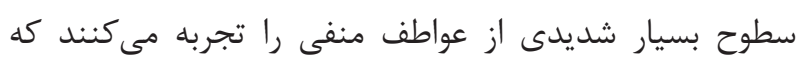
راهبردهاى تنظيم هيجان معمول، براى مقابله با اين هيجانات، مؤثر نيست. يكى از تبيينهاى مطرح شده براى اين است كه افراد

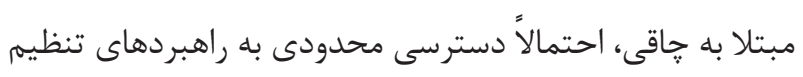

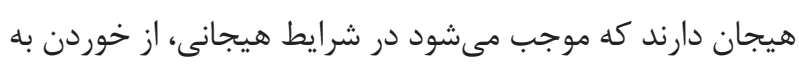

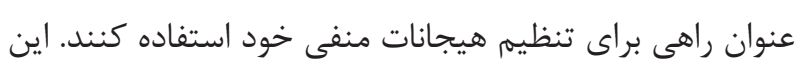

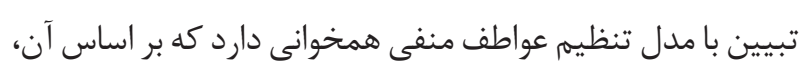

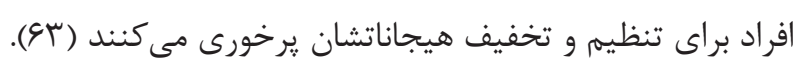

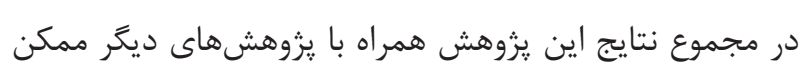

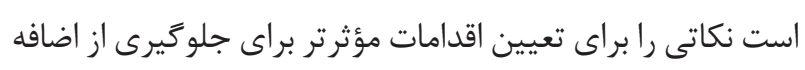
وزن، حاقى يا كم وزن يا مداخله كنترل وزن ارائه دهد. يِيشنهاد

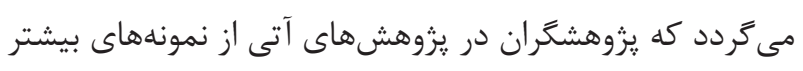

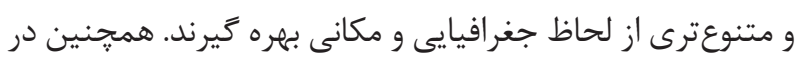
يروهشهاى آينده متغيرهاى يزوهش بر روى افرادى كه از نظر إنى

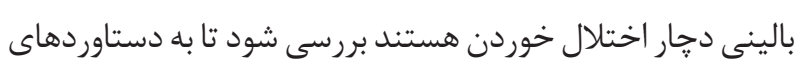

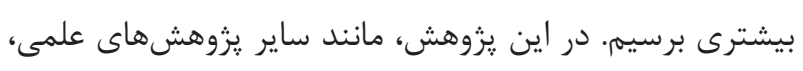

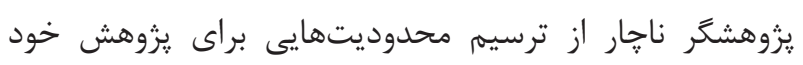

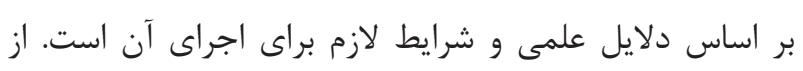

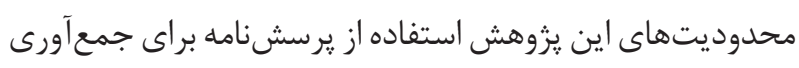

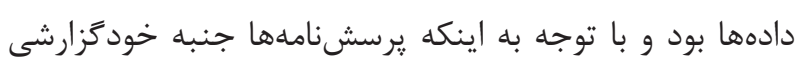

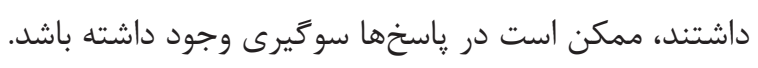

\section{تشكر و قدردانى}

نويسند حاضر شركت كردند صميمانه تشكر كنند.

\section{تضاد منافع}

هيج كونه تضاد منافع در اين مطالعه بين يزووهشكران و نويسندگًان مقاله وجود نداشت. - مئ.

$$
\text { رفتارى و تجربى را تحت تأثير قرار مىدهد (YV). }
$$

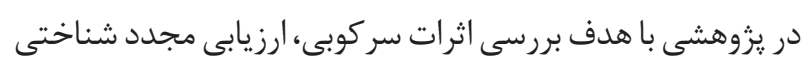

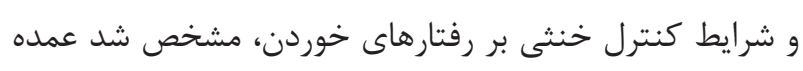

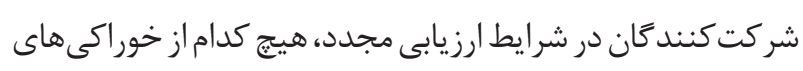

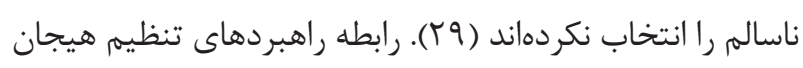
ناسازگار با عاطفه منفى، بريشانى روانشناختى و خوردن بيشتر

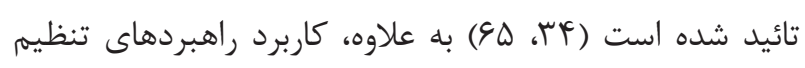
هيجان ساز كار (ارزيابى مجدد شناختى و يذيرش)، در ايجاد سطح

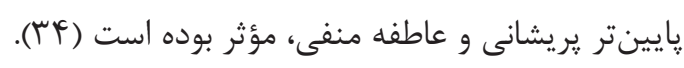

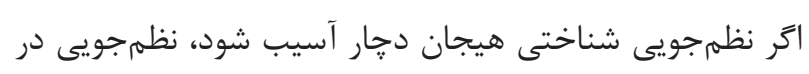

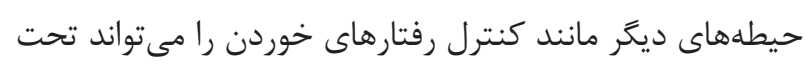

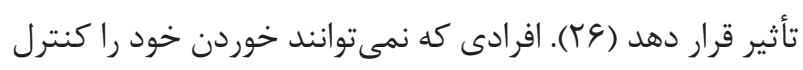

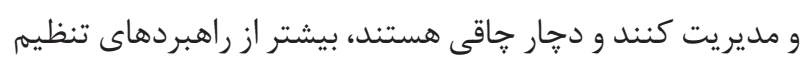

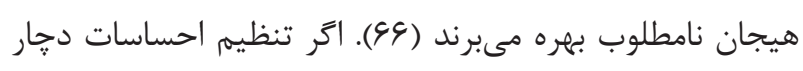

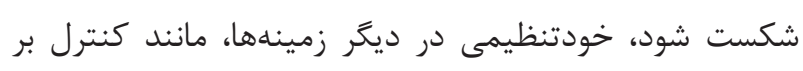

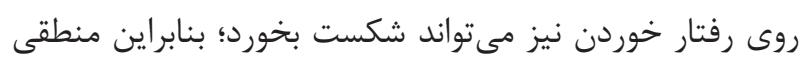

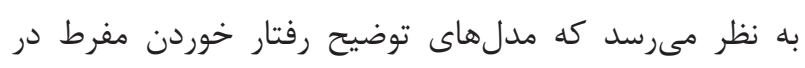

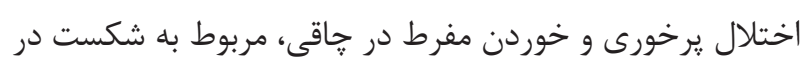

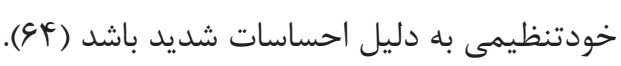

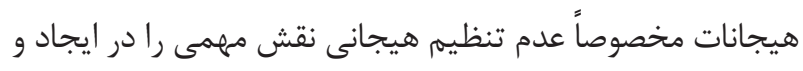

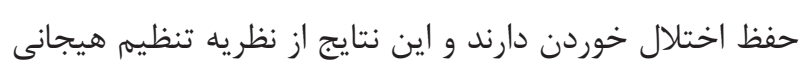

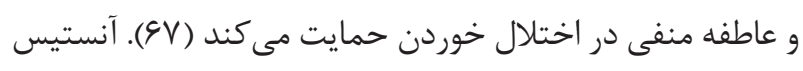
و همكاران (Anestis)

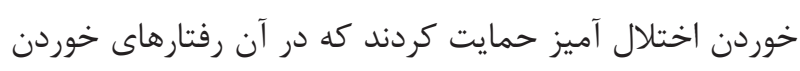
مختل شده به دليل تلاش براى كاهش عواطف منفى ايجاد شده

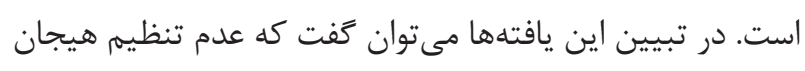

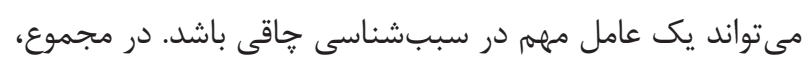

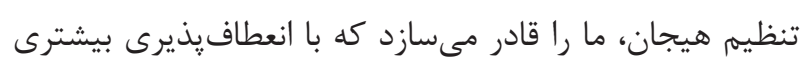

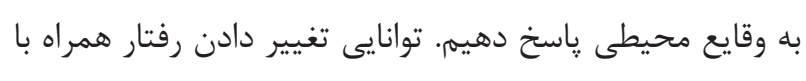

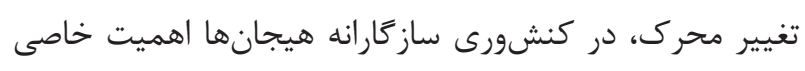

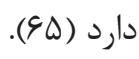




\section{References}

1- Sadeghi K, Gharaie B, Fati L, Mazhari A. The Effectiveness of Cognitive Behavioral Therapy in the Treatment of Obese Patients. Iranian Journal of Psychiatry and Clinical Psychology. 2016;16(2):107-17.

2- Kachoie M, Ashrafi E. Investigating factor structure, reliability and validity of food craving-adjective questionnaire in Iranian adults. Journal of Kerman University of Medical Sciences. 2016;23(5):631-48.

3- Baker T, Morse E, Sherman H. The motivation to use drugs: A psychobiological analysis of urges. Nebr Symp Motiv. 1986;34:257-323.

4- Zilabi Sadegani E, Sabahi P, Rafieniya P. The Effect of Directaneous Skin Stimulation on Decreased Food Craving and Food-Related Implicit Memory Browsing: Semnan University; 2016.

5- Fatahi S, Naderi F, Askari P, Ahadi H. Effectiveness of neurofeedback education on the craving for food and the overall health of overweight women. Health Psychology Journal. 2017;6(1):129-41.

6- Schlundt DG, Virts KL, Sbrocco T, Pope-Cordle J, Hill JO. A sequential behavioral analysis of cravings sweets in obese women. Addictive Behaviors. 1993;18(1):67-80. DOI: 10.1016/03064603(93)90010-7

7- Dye L, Warner P, Bancroft J. Food craving during the menstrual cycle and its relationship to stress, happiness of relationship and depression; a preliminary enquiry. J Affective Disorders. 1995;34(3):157-64. DOI: 10.1016/0165-0327(95)00013-d

8- Gendall KA, Sullivan PF, Joyce PR, Bulik CM. Food cravings in women with a history of anorexia nervosa. Inter J Eating Disorders. 1997;22(4):403-9. DOI: 10.1002/(sici)1098108x(199712)22:4<403::Aid-eat5>3.0.Co;2-q

9- Fedoroff IC, Polivy J, Herman CP. The effect of pre-exposure to food cues on the eating behavior of restrained and unrestrained eaters. Appetite. 1997;28(1):33-47. DOI: 10.1006/appe.1996.0057 PMID: 9134093

10- Cepeda-Benito A, Gleaves DH, Williams TL, Erath SA. The development and validation of the state and trait food-cravings questionnaires. Behavior Therapy. 2000;31(1):151-73. DOI: 10.1016/s0005-7894(00)80009-x

11- Moreno S, Rodriguez S, Fernandez MC, Tamez J, Cepeda-Benito A. Clinical validation of the trait and state versions of the Food Craving Questionnaire. Assessment. 2008;15(3):375-87. DOI: 10.1177/1073191107312651 PMID: 18310596

12- Meule A, Kubler A. Food cravings in food addiction: the distinct role of positive reinforcement. Eat Behav. 2012;13(3):252-5. DOI: 10.1016/j.eatbeh.2012.02.001 PMID: 22664405

13- Vander Wal JS, Johnston KA, Dhurandhar NV. Psychometric properties of the State and Trait Food Cravings Questionnaires among overweight and obese persons. Eat Behav. 2007;8(2):21123. DOI: 10.1016/j.eatbeh.2006.06.002 PMID: 17336791
14- Khodapanah Ms, Ahadi H, Taghiloo S. Mediating Role of Cognitive Emotion Regulation in the Relationship between BrainBehavioral Systems and Eating Behaviors in Individuals with Overweight and Obesity. J Rese Psychological Health. 2018;11(4).

15- Strickland CM. Validating the personality inventory for DSM-5: A trait-based model of personality disorders. The Florida State University. 2014.

16- Samuel DB, Hopwood CJ, Krueger RF, Thomas KM, Ruggero CJ. Comparing methods for scoring personality disorder types using maladaptive traits in DSM-5. Assessment. 2013;20(3):353-61. DOI: 10.1177/1073191113486182 PMID: 23588686

17- De Cock N, Van Lippevelde W, Goossens L, De Clercq B, Vangeel J, Lachat C, et al. Sensitivity to reward and adolescents' unhealthy snacking and drinking behavior: the role of hedonic eating styles and availability. Int J Behav Nutr Phys Act. 2016;13:17. DOI: 10.1186/s12966-016-0341-6 PMID: 26861539

18- Griffioen-Roose S, Hogenkamp PS, Mars M, Finlayson G, de Graaf C. Taste of a 24-h diet and its effect on subsequent food preferences and satiety. Appetite. 2012;59(1):1-8. DOI: 10.1016/j. appet.2012.03.013 PMID: 22445775

19- Pickering AD, Corr PJ. J.A. Gray's Reinforcement Sensitivity Theory (RST) of Personality. The SAGE Handbook of Personality Theory and Assessment: Volume 1 - Personality Theories and Models2008. p. 239-56.

20- Heaven PC, Mulligan K, Merrilees R, Woods T, Fairooz Y. Neuroticism and conscientiousness as predictors of emotional, external, and restrained eating behaviors. Int $\mathrm{J}$ Eat Disord. 2001;30(2):161-6. DOI: 10.1002/eat.1068 PMID: 11449449

21- Gerlach G, Herpertz S, Loeber S. Personality traits and obesity: a systematic review. Obes Rev. 2015;16(1):32-63. DOI: 10.1111/ obr.12235 PMID: 25470329

22- Elfhag K, Morey LC. Personality traits and eating behavior in the obese: poor self-control in emotional and external eating but personality assets in restrained eating. Eat Behav. 2008;9(3):28593. DOI: 10.1016/j.eatbeh.2007.10.003 PMID: 18549987

23- Provencher V, Begin C, Gagnon-Girouard MP, Tremblay A, Boivin S, Lemieux S. Personality traits in overweight and obese women: associations with BMI and eating behaviors. Eat Behav. 2008;9(3):294-302. DOI: 10.1016/j.eatbeh.2007.10.004 PMID: 18549988

24- Opolski M, Chur-Hansen A, Wittert G. The eating-related behaviours, disorders and expectations of candidates for bariatric surgery. Clin Obes. 2015;5(4):165-97. DOI: 10.1111/cob.12104 PMID: 26173752

25- Miller-Matero LR, Armstrong R, McCulloch K, Hyde-Nolan M, Eshelman A, Genaw J. To eat or not to eat; is that really the question? An evaluation of problematic eating behaviors and mental health among bariatric surgery candidates. Eat Weight Disord. 2014;19(3):377-82. DOI: 10.1007/s40519-014-0118-3 PMID: 24878835 
26- Heatherton TF, Wagner DD. Cognitive neuroscience of selfregulation failure. Trends Cogn Sci. 2011;15(3):132-9. DOI: 10.1016/j.tics.2010.12.005 PMID: 21273114

27- Mohammadi Khoshoie M, Karimi A, Rismanchian M. The Effect of Teaching Adjustment Techniques on Weight Loss in Obesity Women. Contemporary Psychology (Special Letter). 2017; 12:1562-5.

28- Eisenberg N, Fabes RA, Guthrie IK, Reiser M. Dispositional emotionality and regulation: their role in predicting quality of social functioning. J Pers Soc Psychol. 2000;78(1):136-57. DOI: 10.1037//0022-3514.78.1.136 PMID: 10653511

29- Kachoie M, Moradi A, Sadati Kazemi A, Ghanbari Z. The distinctive role of regulating excitement and impulsivity in various types of unhealthy eating patterns. Wo Monthly Feyz. 2016;20(4):383-90.

30- Zebardast O, Beshareat M, Poorhoeoin R, Bahrami H, Poor sharifi H. Comparison of the Effectiveness of Interpersonal Therapy and Emotional Management on Weight Loss in Obese and Overweight Women. Health Psychology J. 2015;4(3):50-75.

31- Mirzamohammad Alaeini E, Alipoor A, Noorbala A, Agah heris M. The Effectiveness of Eating Eating Moderation Intervention on Eating Eating Disorders and Managing the Weight of Obese and Overweight Women. Health Psychology Journal. 2013;2(7):21-32.

32- Sayahi M. The prediction of obesity in girls based on cognitive emotional regulation and stress coping strategies. The 5th National Conference on the Development and Promotion of Educational Sciences, Psychology, Advice and Education in Iran; Iran2017. p. $1-8$.

33- Taut D, Renner B, Baban A. Reappraise the Situation but Express Your Emotions: Impact of Emotion Regulation Strategies on ad libitum Food Intake. Front Psychol. 2012;3:359. DOI: 10.3389/ fpsyg.2012.00359 PMID: 23055994

34- Zare H, Selghi Z. The Relationship between Cognitive Emotion Regulatory Strategies and Depression, Anxiety and Stress in Students. Journal of Research in Psychological Health. 2012;6(3):19-29.

35- Micanti F, Iasevoli F, Cucciniello C, Costabile R, Loiarro G, Pecoraro $\mathrm{G}$, et al. The relationship between emotional regulation and eating behaviour: a multidimensional analysis of obesity psychopathology. Eat Weight Disord. 2017;22(1):105-15. DOI: 10.1007/s40519-016-0275-7 PMID: 27068173

36- Aghayousefi AT, Farmani A. The role of the five great factors of personality in predicting emotional adjustment cognitive strategies by mediating the elements of patience in order to present the model. Quarterly Journal of Clinical Psychology. 2017;7(26):4363.

37- Gresham D, Gullone E. Emotion regulation strategy use in children and adolescents: The explanatory roles of personality and attachment. Personality and Individual Differences. 2012;52(5):616-21. DOI: 10.1016/j.paid.2011.12.016

38- Cabello R, Salguero JM, Fernández-Berrocal P, Gross JJ. A Spanish Adaptation of the Emotion Regulation Questionnaire.
European J Psychological Assessment. 2013;29(4):234-40. DOI: 10.1027/1015-5759/a000150

39- Johnsen SÅK. Exploring the use of nature for emotion regulation: Associations with personality, perceived stress, and restorative outcomes. Nordic Psychology. 2013;65(4):306-21. DOI: 10.1080/19012276.2013.851445

40- Cepeda-Benito A, Gleaves D, Fernández MC, Vila J, Williams TL, Reynoso J. The development and validation of Spanish versions of the state and trait food cravings questionnaires. . Behav Res Ther. 2000;38(11):1125-38. DOI: 10.1037/t16231-000

41- Cepeda-Benito A, Fernandez MC, Moreno S. Relationship of gender and eating disorder symptoms to reported cravings for food: construct validation of state and trait craving questionnaires in Spanish. Appetite. 2003;40(1):47-54. DOI: 10.1016/s01956663(02)00145-9

42- Krueger RF, Derringer J, Markon KE, Watson D, Skodol AE. Initial construction of a maladaptive personality trait model and inventory for DSM-5. Psychol Med. 2012;42(9):1879-90. DOI: 10.1017/S0033291711002674 PMID: 22153017

43- Krueger RF, Eaton NR, Clark LA, Watson D, Markon KE, Derringer J, et al. Deriving an empirical structure of personality pathology for DSM-5. J Pers Disord. 2011;25(2):170-91. DOI: 10.1521/pedi.2011.25.2.170 PMID: 21466248

44- Wright AG, Thomas KM, Hopwood CJ, Markon KE, Pincus AL, Krueger RF. The hierarchical structure of DSM-5 pathological personality traits. J Abnorm Psychol. 2012;121(4):951-7. DOI: 10.1037/a0027669 PMID: 22448740

45- Abdi R, Chalbianlo G. Adaptation and review of the psychometric features of the short form of the personality questionnaire. The fifth edition of the Diagnostic and Statistical Manual of Mental Disorders. Quarter J Adva Psycho Rese. 2017;12(45):132-54.

46- Garnefski N, Kraaij V. Cognitive emotion regulation questionnaire - development of a short 18-item version (CERQ-short). Personality and Individual Differences. 2006;41(6):1045-53. DOI: 10.1016/j.paid.2006.04.010

47- Garnefski N, Kraaij V, Spinhoven P. Negative life events, cognitive emotion regulation and emotional problems. Personality and Individual Differences. 2001;30(8):1311-27. DOI: 10.1016/ s0191-8869(00)00113-6

48- Beshareat M, Zahedi Tajrishi K, Noorbala A. Comparison of emotional collapse and emotion regulation strategies in patients with physicalization, anxiety and normal people. Journal of Contemporary Psychology. 2013;8(2):3-16.

49- Besharat M, Bazzazian S. Psychometri properties of the Cognitive Emotion Regulation Questionnaire in a sample of Iranian population. 2013;24(84):61-9.

50- Faith MS, Flint J, Fairburn CG, Goodwin GM, Allison DB. Gender differences in the relationship between personality dimensions and relative body weight. Obes Res. 2001;9(10):647-50. DOI: 10.1038/oby.2001.86 PMID: 11595783

51- Behzadipoor S, Rezaie Karegar F, Sepah Mansoor M, Nooh S. Characteristics of personality and defense mechanisms of obese 
people compared to those with normal weight. Magazine of Thought and Behavior. 2011;6(21):25-34.

52- Kakizaki M, Kuriyama S, Sato Y, Shimazu T, Matsuda-Ohmori K, Nakaya N, et al. Personality and body mass index: a crosssectional analysis from the Miyagi Cohort Study. J Psychosom Res. 2008;64(1):71-80. DOI: 10.1016/j.jpsychores.2007.07.008 PMID: 18158002

53- Costa PT, McCrae RR. Four ways five factors are basic. Personality and Individual Differences. 1992;13(6):653-65. DOI: 10.1016/0191-8869(92)90236-i

54- Feldman PJ, Cohen S, Doyle WJ, Skoner DP, Gwaltney JM, Jr. The impact of personality on the reporting of unfounded symptoms and illness. J Pers Soc Psychol. 1999;77(2):370-8. DOI: 10.1037//0022-3514.77.2.370 PMID: 10474212

55- Neitzert CS, Davis C, Kennedy SH. Personality factors related to the prevalence of somatic symptoms and medical complaints in a healthy student population. Br J Med Psychol. 1997;70 ( Pt 1):93101. DOI: 10.1111/j.2044-8341.1997.tb01889.x PMID: 9093754

56- Sutin AR, Terracciano A. Personality traits and body mass index: Modifiers and mechanisms. Psychol Health. 2016;31(3):259-75. DOI: 10.1080/08870446.2015.1082561 PMID: 26274568

57- Davis C. Compulsive Overeating as an Addictive Behavior: Overlap Between Food Addiction and Binge Eating Disorder. Current Obesity Reports. 2013;2(2):171-8. DOI: 10.1007/s13679013-0049-8

58- Evenden JL. Varieties of impulsivity. Psychopharmacology (Berl). 1999;146(4):348-61. DOI: 10.1007/p100005481 PMID: 10550486

59- Mobbs O, Crepin C, Thiery C, Golay A, Van der Linden M. Obesity and the four facets of impulsivity. Patient Educ Couns. 2010;79(3):372-7. DOI: 10.1016/j.pec.2010.03.003 PMID: 20399590

60- Thamotharan S, Lange K, Zale EL, Huffhines L, Fields S. The role of impulsivity in pediatric obesity and weight status: a meta- analytic review. Clin Psychol Rev. 2013;33(2):253-62. DOI: 10.1016/j.cpr.2012.12.001 PMID: 23313762

61- Khabir L, Karam Bakhsh G, Mohammadi N. Impact Relationship with Body Mass Index: The role of mediator of food addiction. Health Psychology J. 2017;6(4):106-19.

62- Spielberger CD, Reheiser EC. Psychological defense mechanisms, motivation and the use of tobacco. Personality and Individual Differences. 2006;41(6):1033-43. DOI: 10.1016/j. paid.2006.04.009

63- Khodapanah Ms, Ahadi H, Taghiloo S. Mediating Role of Cognitive Emotion Regulation in the Relationship between BrainBehavioral Systems and Eating Behaviors in Individuals with Overweight and Obesity. Journal of Research in Psychological Health. 2018;11(52-67).

64- Leehr EJ, Krohmer K, Schag K, Dresler T, Zipfel S, Giel KE. Emotion regulation model in binge eating disorder and obesity--a systematic review. Neurosci Biobehav Rev. 2015;49:125-34. DOI: 10.1016/j.neubiorev.2014.12.008 PMID: 25530255

65- Shahsavari M, Fathiashtiani A, Rasoolzade Tabatabaie K. Body Mass Index: Comparing the excitement and eating behavior. Journal of Lorestan University of Medical Sciences. 2016;18(3):104-13.

66- Czaja J, Rief W, Hilbert A. Emotion regulation and binge eating in children. Int J Eat Disord. 2009;42(4):356-62. DOI: 10.1002/ eat.20630 PMID: 19040265

67- Markey MA, Vander Wal JS. The role of emotional intelligence and negative affect in bulimic symptomatology. Compr Psychiatry. 2007;48(5):458-64. DOI: 10.1016/j.comppsych.2007.05.006 PMID: 17707255

68- Anestis MD, Selby EA, Fink EL, Joiner TE. The multifaceted role of distress tolerance in dysregulated eating behaviors. Int $\mathrm{J}$ Eat Disord. 2007;40(8):718-26. DOI: 10.1002/eat.20471 PMID: 17868125 